Article

\title{
Effect of Calcination Time on the Physicochemical Properties and Photocatalytic Performance of Carbon and Nitrogen Co-Doped $\mathrm{TiO}_{2}$ Nanoparticles
}

Emile Salomon Massima Mouele ${ }^{1, *}$, Mihaela Dinu ${ }^{2}{ }^{\oplus}$, Franscious Cummings ${ }^{3}$, Ojo O. Fatoba ${ }^{1}$,

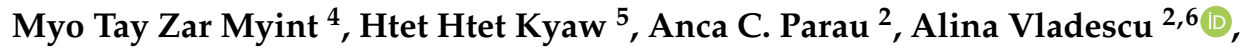

M. Grazia Francesconi ${ }^{7}{ }^{(0}$, Sara Pescetelli ${ }^{8}{ }^{\circ}$, Aldo Di Carlo ${ }^{8,9}{ }^{\circledR}$, Antonio Agresti ${ }^{8,9}{ }^{\circledR}$, Mohammed Al-Abri ${ }^{5,10}$, Sergey Dobretsov ${ }^{11,12}$ (-) , Mariana Braic ${ }^{2}(1)$ and Leslie F. Petrik ${ }^{1, *}$ (i)

1 Environmental Nano Science (ENS) research group, Department of Chemistry, UWC, Bellville 7535, South Africa; larryfat2006@gmail.com

2 Research Center for Advanced Surface Processing and Analysis by Vacuum Technologies (ReCAST), National Institute for Research and development in Optoelectronics INOE 2000, Magurele, 077125 Bucharest, Romania; mihaela.dinu@inoe.ro (M.D.); anca.parau@inoe.ro (A.C.P.); alinava@inoe.ro (A.V.); mariana.braic@inoe.ro (M.B.)

3 Electron Microscope Unit, Department of Physics and Astronomy, University of the Western Cape, Bellville 7535, South Africa; fcummings@uwc.ac.za

4 Department of Physics, College of Science, Sultan Qaboos University, P.O. Box 36, 123 Al-Khoud, Muscat 123, Oman; myomyint@squ.edu.om

5 Nanotechnology Research Center, Sultan Qaboos University, P.O. Box 33, Al-Khoud, Muscat 123, Oman; htethtetkyaw2006@gmail.com (H.H.K.); Alabri@squ.edu.om (M.A.-A.)

6 Physical Materials Science and Composite Materials Centre, National Research Tomsk Polytechnic University, Lenin Avenue 43, 634050 Tomsk, Russia

7 Department of Chemistry and Biochemistry, University of Hull, Hull HU6 7RX, UK; M.G.Francesconi@hull.ac.uk

8 CHOSE, Electronic Engineering Department University of Rome Tor Vergata, Via del Politecnico 1, 00133 Rome, Italy; pescetel@uniroma2.it (S.P.); aldo.dicarlo@uniroma2.it (A.D.C.); antonio.agresti@uniroma2.it (A.A.)

9 LASE, National University of Science and Technology “MISiS", Leninsky Ave. 6, Moscow 119049, Russia

10 Petroleum and Chemical Engineering Department, Sultan Qaboos University, P.O. Box 33, Al-Khoud, Muscat 123, Oman

11 Department of Marine Science and Fisheries, Sultan Qaboos University, P.O. Box 34, Al-Khoud, Muscat 123, Oman; sergey@squ.edu.om

12 Center of Excellence in Marine Biotechnology, Sultan Qaboos University, P.O. Box 50, Al-Khoud, Muscat 123, Oman

* Correspondence: emilemassima@yahoo.fr (E.S.M.M.); lpetrik@uwc.ac.za (L.F.P.); Tel.: +27-7-8851-3087 (E.S.M.M.); +(21)-9593304 (L.F.P.)

Received: 19 May 2020; Accepted: 10 July 2020; Published: 28 July 2020

Abstract: The application of highly active nano catalysts in advanced oxidation processes (AOPs) improves the production of non-selective hydroxyl radicals and co-oxidants for complete remediation of polluted water. This study focused on the synthesis and characterisation of a highly active visible light $\mathrm{C}-\mathrm{N}$-co-doped $\mathrm{TiO}_{2}$ nano catalyst that we prepared via the sol-gel method and pyrolysed at $350{ }^{\circ} \mathrm{C}$ for $105 \mathrm{~min}$ in an inert atmosphere to prevent combustion of carbon moieties. Then we prolonged the pyrolysis holding time to 120 and $135 \mathrm{~min}$ and studied the effect of these changes on the crystal structure, particle size and morphology, electronic properties and photocatalytic performance. The physico-chemical characterisation proved that alteration of pyrolysis holding time allows control of the amount of carbon in the $\mathrm{TiO}_{2}$ catalyst causing variations in the band gap, particle size and morphology and induced changes in electronic properties. The $\mathrm{C}-\mathrm{N}-\mathrm{TiO}_{2}$ nano composites were active under both visible and UV light. Their improved activity was ascribed to a low electron-hole 
pair recombination rate that enhanced the generation of $\mathrm{OH} \cdot$ and related oxidants for total deactivation of O.II dye. This study shows that subtle differences in catalyst preparation conditions affect its physico-chemical properties and catalytic efficiency under solar and UV light.

Keywords: nano-photo catalysts; pyrolysis; holding time; band gap; crystal structure; particle size; photocatalytic activity; recombination rate

\section{Introduction}

The accumulation of persistent organic pollutants (POPs) in water sources demonstrates the failure of conventional treatment methods for complete removal of these xenotoxins [1]. Direct oxidation of POPs in water could be an alternative remediation route to remove these pollutants. Advanced oxidation processes (AOPs), such as $\mathrm{O}_{3} / \mathrm{UV}, \mathrm{H}_{2} \mathrm{O}_{2} / \mathrm{UV}, \mathrm{O}_{3} / \mathrm{UV} / \mathrm{H}_{2} \mathrm{O}_{2}$, UV/catalysts, etc., have been considered as effective oxidative methods in producing non-selective hydroxyl radical and persulfate oxidants for degrading such pollutants [2-6]. The efficiency of AOPs varies according to the amount of $\mathrm{OH} \cdot$ generated.

Recently, the use of semiconductor photo catalysts in AOPs has been shown to be an active method to improve the yield of $\mathrm{OH}$. in water treatment processes [7-9]. Titanium dioxide $\left(\mathrm{TiO}_{2}\right)$ that is often found in anatase, brookite or rutile forms is a less costly, stable photo catalyst and has commonly been utilised in powder form for photo catalytic removal of organic pollutants from water and wastewater $[10,11]$. Its large band gap of $3.2 \mathrm{eV}$ that is mostly active only under UV light has become a limitation for solar systems. The tuning of $\mathrm{TiO}_{2}$ absorption band from the $\mathrm{UV}$ range to visible region has been the subject of diverse research investigations [12-14].

From this point of view, the structural manipulation of semi-conductor composites has gained serious attention in photo catalysis. The valence band (VB) of $\mathrm{TiO}_{2}$ consists of $2 \mathrm{p}$ orbitals of oxygen while the $3 \mathrm{~d}$ orbitals of titanium govern the conducting band (CB) [15]. Hence, the modification of the $\mathrm{TiO}_{2}$ band structure entails that the electron-hole pairs generated on both $\mathrm{VB}$ and $\mathrm{CB}$ absorb visible or UV light, while the band edge on top of the VB and below the $\mathrm{CB}$ should not be excessively altered which might compromise $\mathrm{TiO}_{2}$ photo activity [16].

The doping process using metal loading [17] or by incorporation of non-metals, such as $C$ and $\mathrm{N}$, has been used as a common principle to diminish the $\mathrm{TiO}_{2}$ band gap to the visible range and to reduce the electron-hole recombination [18-20]. Alternatively, the band gap tuning relates to using more visible light but reducing electron recombination could be more effective for UV light application. $\mathrm{Yu}$ and co-workers [21] established a practical method for instantaneous doping of carbon and nitrogen in $\mathrm{TiO}_{2}$ by annealing titanium carbonitride in air at temperatures between 400 and $700{ }^{\circ} \mathrm{C}$ and time ranging from 3 to $12 \mathrm{~h}$. The results of their study showed that the synthesised $\mathrm{C}-\mathrm{N}-\mathrm{TiO}_{2}$ annealed at $400{ }^{\circ} \mathrm{C}$ for $8 \mathrm{~h}$ was highly photo catalytically active under visible light which further reduced the recombination rate of electron hole pairs. It could be noticed that their route for conversion of $\mathrm{Ti}_{2} \mathrm{CN}$ to powder $\mathrm{C}-\mathrm{N}-\mathrm{TiO}_{2}$ nano catalyst by an annealing process is time and energy consuming and suggests that more advanced methods leading to the synthesis of photo catalysts in a short period of time at milder conditions is of interest.

A similar study was carried out by Li et al. [22] who employed a one-step microwave (MW) irradiation technique for the incorporation of carbon and nitrogen atoms into $\mathrm{TiO}_{2}$ lattice and the prepared $\mathrm{C}-\mathrm{N}-\mathrm{TiO}_{2}$ catalyst was simultaneously deposited onto common brick ((C, N)- $\mathrm{TiO}_{2} /$ brick). The outcomes showed that the porous surface of $(\mathrm{C}, \mathrm{N})-\mathrm{TiO}_{2} /$ brick considerably improved the surface area of the sample that resulted in a longer lifetime for photo-produced electron-hole pairs, and consequently enhanced the photocatalytic properties of the composites. However, the effect of calcination holding time in the air on the properties of the prepared $(\mathrm{C}, \mathrm{N})-\mathrm{TiO}_{2} /$ brick was not 
mentioned in their study, recalling that calcination combusts the carbon whereas pyrolysis causes controlled degradation.

The manufacturing of $\mathrm{C}-\mathrm{N}-\mathrm{TiO}_{2}$ nano composites was also conducted by a few authors using different methods $[23,24]$. Even though these studies sustained that the methods for engineering of $\mathrm{C}-\mathrm{N}-\mathrm{TiO}_{2}$ catalysts were cost effective, efficient and environmental benign, parameters such as calcination holding time on the physical and chemical properties were not fully investigated. On the contrary, introduction of substituents in the $\mathrm{TiO}_{2}$ framework often results in a decrease or an explained increase of its band gap $[13,15]$.

Hence, the alteration of the $\mathrm{TiO}_{2}$ absorption energy band and reduction of electron-hole pairs' recombination are still on-going research fields as a full comprehension of the interaction between dopants or impurities and the $\mathrm{TiO}_{2}$ lattice is still challenging and difficult to control systematically. Furthermore, the physico-chemical properties and the reactivity of photo catalysts such as $\mathrm{TiO}_{2}$ may depend on the synthesis method [10]. The sol-gel method has been found practical due to its operational ease and low cost $[19,20]$.

Other authors claimed that the crystal structure, band gap, size distribution, surface area, porosity and surface hydroxyl density may impact upon the activity of $\mathrm{TiO}_{2}$ [11] but in most of these studies the impact of annealing holding time on the aforementioned properties have not been elucidated. Therefore, a critical investigation of the impact of calcination holding time on the physico-chemical properties of the sol-gel synthesised $\mathrm{TiO}_{2}$ based catalysts is still an open research field aiming at understanding the limitations of $\mathrm{TiO}_{2}$ efficacy.

Herein, we synthesised a $\mathrm{C}-\mathrm{N}-\mathrm{TiO}_{2}$ nano catalyst by a simple and rapid sol-gel method using polyacrilonitrile (PAN) and $\mathrm{TiCl}_{4}$ as precursors followed by pyrolysis in $\mathrm{N}_{2}$. The impact of annealing using pyrolysis holding time to control crystal structure, shape, size was examined. Furthermore, the influence of pyrolysis holding time on the activity of the nanostructured $\mathrm{C}-\mathrm{N}-\mathrm{TiO}_{2}$ was evaluated for the degradation of orange II sodium salt dye under UV light. Overall, the aim of this study was to engineer a stable and active $\mathrm{C}-\mathrm{N}-\mathrm{TiO}_{2}$ photo catalyst by sol-gel protocols for future incorporation in solar and UV based advanced oxidation processes (AOPs) to boost the total removal of persistent organic pollutants under UV light.

\section{Results}

\subsection{X-Ray Diffraction and Raman Spectroscopy Analysis of the Synthesized Catalysts}

The XRD analysis and Raman spectroscopy were used to determine the phase composition, particle size and the crystallinity of $\mathrm{TiO}_{2}$ and $\mathrm{C}-\mathrm{N}-\mathrm{TiO}_{2}$ co-doped nano particles and the results of this analysis are presented in Figure 1a,b.

Figure 1a shows that pure Degussa $\mathrm{TiO}_{2}$ consisted of both anatase (JCPDS, No. 00-021-1272) and rutile phases (JCPDS, No. 00-021-1276) with the anatase phase being predominant as indicated by its peak intensities. The pure mineral anatase phase was characterised by the following diffraction peaks $2 \theta=25.28^{\circ}(101), 36.9^{\circ}(103), 37.8^{\circ}(004), 48^{\circ}(200), 53.89^{\circ}(105), 55.06^{\circ}(211), 62.69^{\circ}(204)$, $68.76^{\circ}(116), 70.31^{\circ}(220), 75.03^{\circ}(215)$, and $82.66^{\circ}(224)$ which correspond to the body-centred tetragonal lattice structure of the pure mineral anatase phase. Raman spectra in Figure $1 \mathrm{~b}$ show the dominant $\mathrm{TiO}_{2}$ peak at $157.39 \mathrm{~cm}^{-1}$, while minor peaks depicted at $206.77,397.68,515.42$ and $637.25 \mathrm{~cm}^{-1}$ supplement/confirm the anatase phase highlighted in Figure 1a. 

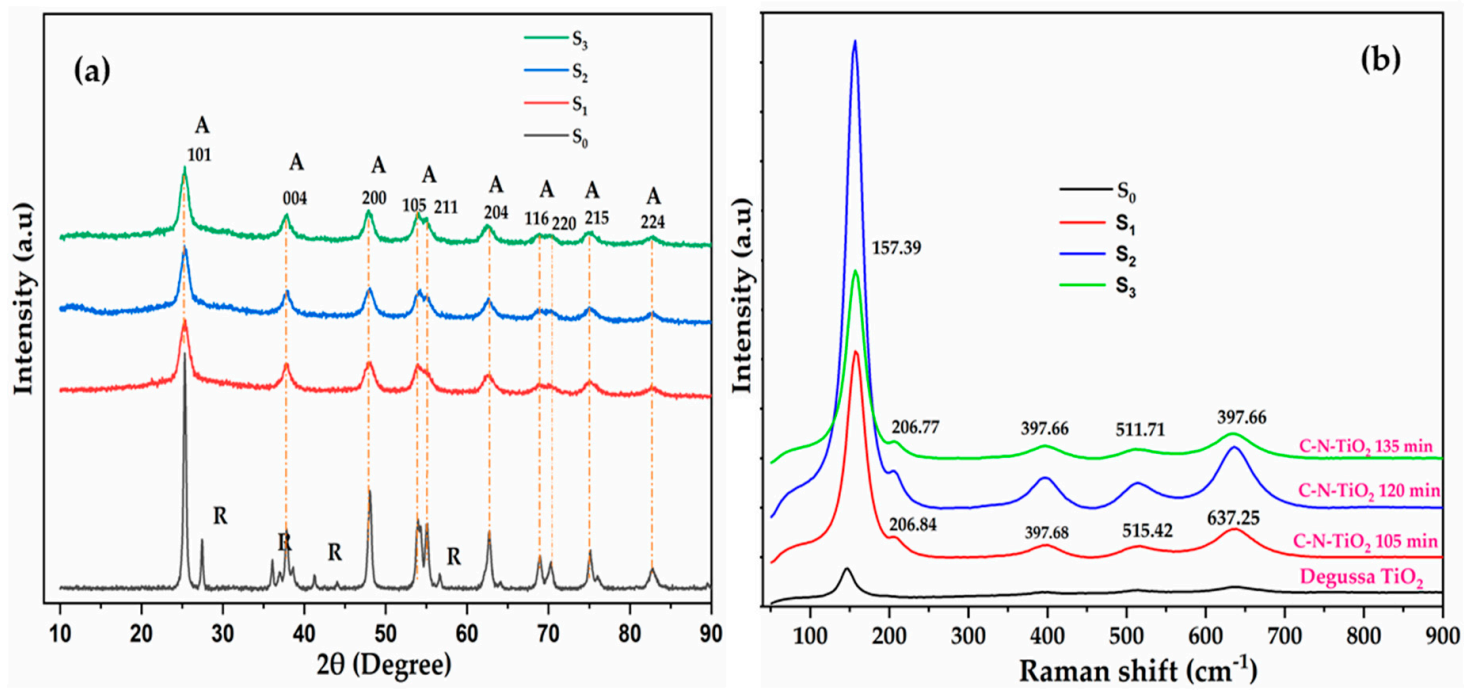

Figure 1. (a) X-ray diffraction (XRD) and (b) Raman analysis of $\mathrm{TiO}_{2}$ Degussa $\left(\mathrm{S}_{0}\right)$ and the synthesised $\mathrm{C}-\mathrm{N}-\mathrm{TiO}_{2}$ nano catalysts pyrolysed at $350{ }^{\circ} \mathrm{C}$, a ramping rate of $50{ }^{\circ} \mathrm{C} / \mathrm{min}$ at different holding times $\left(105 \mathrm{~min}\left(\mathrm{~S}_{1}\right), 120 \mathrm{~min}\left(\mathrm{~S}_{2}\right)\right.$, and $\left.135 \mathrm{~min}\left(\mathrm{~S}_{3}\right)\right)$ with $\mathrm{A}=$ anatase and $\mathrm{R}=$ rutile.

The rutile phase was characterised by the presence of diffraction peaks at $2 \theta=27.44^{\circ}, 36.08^{\circ}, 41.2^{\circ}$, and $55.8^{\circ}$ and 71.29 as from (JCPDS) No. 00-021-1276 corresponding to the tetragonal lattice parameters of the rutile phase. The comparison with the powder X-ray diffraction (PXRD) patterns and the Raman peak of the Degussa catalyst shows that the catalysts synthesised here only contained the anatase phase, although it is difficult to be absolutely certain, due to the broadness of the diffraction peaks. However, it was reported that the formation of the anatase phase occurs, in general, at temperatures below $400{ }^{\circ} \mathrm{C}$ [25].

This meant that the synthesis procedure using the sol-gel protocol followed by pyrolysis resulted mostly in the anatase phase formation which was deemed advantageous for photo catalytic applications due to the small crystalline size, well-crystalline anatase phase and probably constricted band gap $[12,26]$. The size of $\mathrm{TiO}_{2}$ Degussa and $\mathrm{C}-\mathrm{N}-\mathrm{TiO}_{2}$ nano crystals were estimated using the Scherrer Equation (1) [27], and the results are presented in Table 1.

$$
d=\frac{K \times \lambda}{B(2 \theta)} \times \cos \theta
$$

where $d$ is the nano crystal size; $K \approx 0.94$ is a dimensionless shape factor; $\lambda \approx 0.15406 \mathrm{~nm}$ is the $\mathrm{CuK}_{\alpha}$ diffraction wavelength, $B(2 \theta)$ is the line broadening at half the maximum intensity (FWHM), expressed in radians (after subtracting the instrumental line broadening); and $\theta$ is the Bragg angle in degrees.

Table 1. Summary of the average particle sizes of $\mathrm{TiO}_{2}$ Degussa and the synthesised $\mathrm{C}-\mathrm{N}-\mathrm{TiO}$, photo catalysts estimated from XRD analysis using the Scherer equation.

\begin{tabular}{cc}
\hline Photo Catalysts & $\begin{array}{c}\text { Catalyst Size (nm) } \\
\text { XRD (Scherrer Equation) }\end{array}$ \\
\hline $\mathbf{S}_{\mathbf{0}}$ & 21.0 \\
$\mathrm{~S}_{\mathbf{1}}$ & 5.5 \\
$\mathrm{~S}_{\mathbf{2}}$ & 6.3 \\
$\mathrm{~S}_{\mathbf{3}}$ & 6.4 \\
\hline
\end{tabular}

The data presented in Table 1 indicate that the size of the nano-photo catalysts estimated by the Scherrer equation is significantly smaller than the particle size of $\mathrm{TiO}_{2}$ Degussa $\left(\mathrm{S}_{0}\right.$ sample). The result indicates that the production route for co-doped nano $\mathrm{TiO}_{2}$ using the sol-gel/pyrolysis procedure 
promoted the formation of small crystalline domains [12]. The Scherrer equation evaluated the particles size of the three samples $\left(\mathrm{S}_{1}, \mathrm{~S}_{2}\right.$ and $\left.\mathrm{S}_{3}\right)$, not to be too dissimilar (numbers). The XRD results show no peaks characteristic of graphite indicating that, if carbon residues are present, they are in and amorphous form.

\subsection{Fourier Transform Spectroscopy of the Catalysts}

Fourier transforms spectroscopy (FTIR) analysis was further used to elucidate the functional groups present in the synthesised $\mathrm{C}-\mathrm{N}-\mathrm{TiO}_{2}$ catalyst pyrolised at $350{ }^{\circ} \mathrm{C}$ for different holding times and the spectra are shown in Figure 2a.
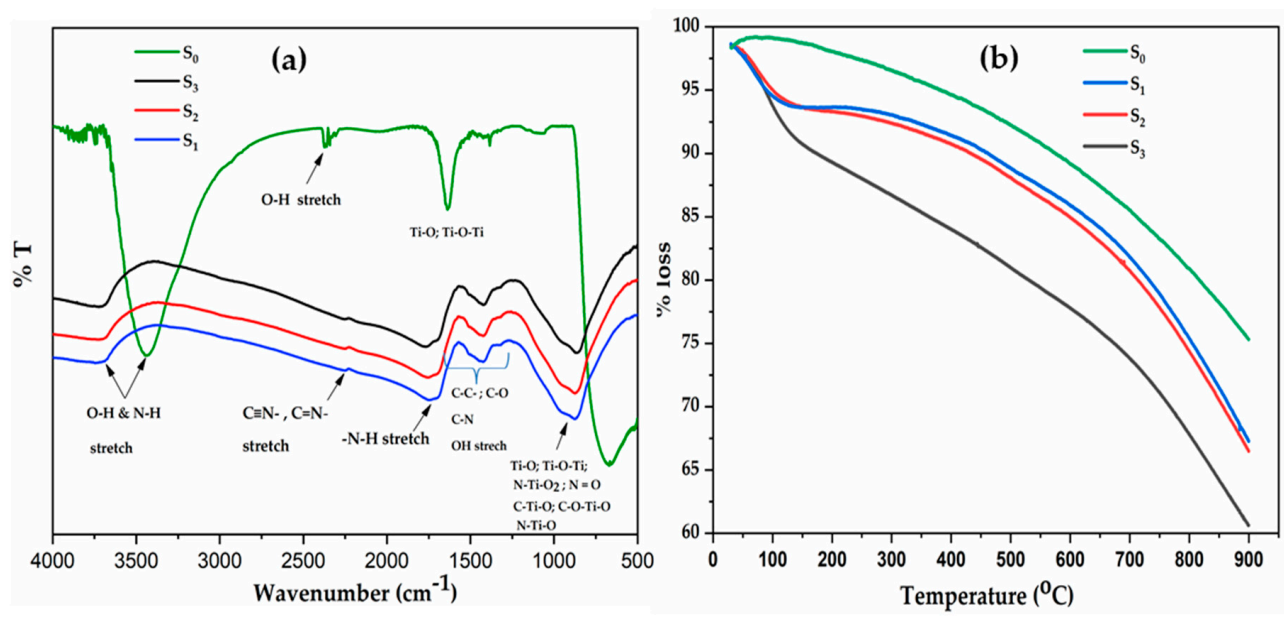

Figure 2. (a) FTIR spectra and (b) thermal gravimetric analysis (TGA) of $\mathrm{C}-\mathrm{N}-\mathrm{TiO}_{2}$ nano composites pyrolysed in nitrogen gas at $350{ }^{\circ} \mathrm{C}$ and held at temperature for different times 105, 120 and $135 \mathrm{~min}$.

Three different absorption bands in all samples were present and are summarised and presented in Table 2. The $\mathrm{OH} / \mathrm{N}-\mathrm{H}$ stretching were identified in $3800-3600 \mathrm{~cm}^{-1}$ region for all catalysts $[26,27]$ as shown in Table 2 as well as peaks relating to $\mathrm{N}-\mathrm{H} ; \mathrm{C}-\mathrm{C}, \mathrm{C}-\mathrm{O}, \mathrm{C}-\mathrm{N}$ and probably $\mathrm{C}=\mathrm{N}, \mathrm{C}=\mathrm{O}, \mathrm{N}=\mathrm{O}$, $\mathrm{OH}$ stretch, etc., that appeared in from $1000-1800 \mathrm{~cm}^{-1}$ and $1800-1200 \mathrm{~cm}^{-1}$ for all catalysts $[26,28]$ which could be ascribed to the decomposition of Polyacrylonitrile (PAN) and $\mathrm{NH}_{4} \mathrm{NO}_{3}$ during pyrolysis at $350{ }^{\circ} \mathrm{C}[29,30]$.

Table 2. Functional groups of the synthesised $\mathrm{C}-\mathrm{N}-\mathrm{TiO}_{2}$ nano catalysts, pyrolysed with nitrogen gas at $350{ }^{\circ} \mathrm{C}$ using a ramping rate of $50{ }^{\circ} \mathrm{C} / \mathrm{min}$ and held at different times $105 \mathrm{~min}\left(\mathrm{~S}_{1}\right), 120 \mathrm{~min}\left(\mathrm{~S}_{2}\right)$ or $135 \mathrm{~min}\left(\mathrm{~S}_{3}\right)$.

\begin{tabular}{|c|c|c|}
\hline Photo Catalysts and Pyrolysis Time (Min) & Absorption Bands $\left(\mathrm{cm}^{-1}\right)$ & Functional Groups/Stretching/Vibrations \\
\hline $\mathrm{S}_{0}$ & $3800-3000,275-1000$ & $\mathrm{OH}$ stretching, $\mathrm{Ti}-\mathrm{O}, \mathrm{Ti}-\mathrm{O}-\mathrm{Ti}$ \\
\hline \multirow{3}{*}{$\mathrm{S}_{1}$} & $3800-3600$ & $\mathrm{OH} / \mathrm{N}-\mathrm{H}$ stretching, etc. \\
\hline & $1900-1800,1800-1200$ & $-\mathrm{N}-\mathrm{H},-\mathrm{C}-\mathrm{C}-, \mathrm{C}-\mathrm{O}$ and $\mathrm{C}-\mathrm{N}, \mathrm{OH}$, stretching, etc. \\
\hline & $1200-700$ & $\begin{array}{l}\mathrm{TiO}, \mathrm{Ti}-\mathrm{O}-\mathrm{Ti}, \mathrm{N}-\mathrm{Ti}-\mathrm{O}_{2}, \mathrm{C}-\mathrm{Ti}-\mathrm{O}, \mathrm{C}-\mathrm{Ti}, \mathrm{C}-\mathrm{O}-\mathrm{Ti}-\mathrm{O}, \\
\mathrm{N}-\mathrm{Ti}-\mathrm{O}, \mathrm{N}=\mathrm{O} \text {, etc. }\end{array}$ \\
\hline \multirow{3}{*}{$\mathrm{S}_{2}$} & $3800-3600$ & $\mathrm{OH} / \mathrm{N}-\mathrm{H}$ stretching, etc. \\
\hline & $1900-1800,1800-1200$ & $-\mathrm{N}-\mathrm{H},-\mathrm{C}-\mathrm{C}-, \mathrm{C}-\mathrm{O}$ and $\mathrm{C}-\mathrm{N}, \mathrm{OH}$, stretching, etc. \\
\hline & $1200-700$ & $\begin{array}{l}\text { Ti-O, Ti-O-Ti, N-Ti-O }, \text { C-O-Ti-O, C-Ti, } \\
\text { N-Ti-O, N=O, etc. }\end{array}$ \\
\hline \multirow{3}{*}{$\mathrm{S}_{3}$} & $3800-3600$ & $\mathrm{OH} / \mathrm{N}-\mathrm{H}$ stretching, etc. \\
\hline & $1900-1800,1800-1200$ & $-\mathrm{N}-\mathrm{H},-\mathrm{C}-\mathrm{C}-, \mathrm{C}-\mathrm{O}$ and $\mathrm{C}-\mathrm{N}, \mathrm{OH}$, stretch, etc. \\
\hline & $1200-700$ & $\begin{array}{l}\mathrm{Ti}-\mathrm{O}, \mathrm{Ti}-\mathrm{O}-\mathrm{Ti}, \mathrm{N}-\mathrm{Ti}-\mathrm{O}_{2}, \mathrm{C}-\mathrm{O}-\mathrm{Ti}-\mathrm{O}, \mathrm{C}-\mathrm{Ti} \text {, } \\
\mathrm{N}-\mathrm{Ti}-\mathrm{O} \mathrm{N}=\mathrm{O} \text {, etc. }\end{array}$ \\
\hline
\end{tabular}


Finally, Ti-O, C-Ti-O, O-Ti-O, N-TiO 2 , Ti-O-Ti and $\mathrm{N}=\mathrm{O}$ stretching are evident in the $1200-500 \mathrm{~cm}^{-1}$ range in all samples demonstrates the bonding of $\mathrm{Ti}, \mathrm{O}$ and $\mathrm{N}$ in $\mathrm{C}-\mathrm{N}-\mathrm{TiO}_{2}$ catalyst [31]. This is also evident from the intensity of FTIR spectra peaks in the same range $\left(1200-700 \mathrm{~cm}^{-1}\right)$ that shifted toward lower wavenumbers as pyrolysis time was increased. The aforementioned functional groups demonstrate the presence of $\mathrm{C}$ and $\mathrm{N}$ associated with the $\mathrm{TiO}_{2}$ semiconductor. The unsaturated functional groups, such as $\mathrm{C}=\mathrm{O}$ and $\mathrm{N}=\mathrm{O}$, resulted from random combinations of unstable $\mathrm{C}$ and $\mathrm{N}$ impurities deposited upon nano- $\mathrm{TiO}_{2}$ during the pyrolysis process.

The pyrolysis process might have further induced the formation of various evaporated gases such as CO, NO, etc. Furthermore, in Table 2, C-Ti bonds were also present at the holding times of 120 and $135 \mathrm{~min}$. However, due to the instability of $\mathrm{C}-\mathrm{Ti}, \mathrm{N}-\mathrm{Ti}$, etc., $\mathrm{C}$ and $\mathrm{N}$ might have evaporated during extended holding times of pyrolysis and caused the band gap to revert closer to that of Degussa $\mathrm{TiO}_{2}$ (see Figure 2).

\subsection{Thermal Gravimetric Analysis of the Synthesised Catalysts}

The TGA outcomes presented in Figure $2 \mathrm{~b}$ show the mass loss of $\mathrm{C}-\mathrm{N}-\mathrm{TiO}_{2}$ nano catalysts over time during pyrolysis in $\mathrm{N}_{2}$. The results indicate that the loss of some volatile components in the synthesised catalysts occurred between 100 and $130{ }^{\circ} \mathrm{C}$. These trends supplement the gas evaporation claimed in the FTIR discussion. With reference to $\mathrm{TiO}_{2}$ Degussa, about $8.7 \%$ of the mass of the $\mathrm{C}-\mathrm{N}-\mathrm{TiO}_{2}(105 \mathrm{~min})$ was lost between $130{ }^{\circ} \mathrm{C}$ and $700{ }^{\circ} \mathrm{C}$, compared to $10 \%$ and $14.65 \%$ mass loss recorded for $\mathrm{C}-\mathrm{N}-\mathrm{TiO}_{2}(120 \mathrm{~min})$ and $\mathrm{C}-\mathrm{N}-\mathrm{TiO}_{2}(135 \mathrm{~min})$, respectively. The increase of the pyrolysis time during the catalyst preparation resulted in an increased loss of volatile components forming part of the catalyst mass loss.

The high mass loss was ascribed mostly to loss of carbonaceous species from PAN degradation and shows that a large amount of $\mathrm{C}$ content in the product was related to the PAN precursor (Table 3). Thus, the catalyst mass loss experienced in this study was probably due to PAN decomposition that occurred between 130 and $700{ }^{\circ} \mathrm{C}$. Indeed, the carbonisation of PAN in $\mathrm{N}_{2}$ gas, certainly led to the cyclisation reaction whereby the nitrile groups appearing at $2261 \mathrm{~cm}^{-1}$ were converted to $\mathrm{C}=\mathrm{N}$ bonds that were evidenced by the FTIR along with $C=C$ and $C-N$ stretching between 1200 and $1800 \mathrm{~cm}^{-1}$ as supported by Sánchez-Soto et al. [32] and Darányi Mári et al. [33].

Table 3. Weight percentage as derived TEM-energy-dispersive spectroscopy (TEM-EDS) of the synthesised nano catalysts pyrolysed at $350^{\circ} \mathrm{C}$ using a $50{ }^{\circ} \mathrm{C} / \mathrm{min}$ ramping rate and holding times of $105 \mathrm{~min}\left(\mathrm{~S}_{1}\right), 120 \mathrm{~min}\left(\mathrm{~S}_{2}\right)$ or $135 \mathrm{~min}\left(\mathrm{~S}_{3}\right)$ under nitrogen.

\begin{tabular}{ccccc}
\hline Elements & \multicolumn{4}{c}{ Weight Percentage (\%) } \\
\hline & $\mathrm{S}_{0}$ & $\mathrm{~S}_{1}$ & $\mathrm{~S}_{2}$ & $\mathrm{~S}_{3}$ \\
\hline $\mathrm{C}$ & $\mathrm{NA}$ & \pm 72.2 & \pm 64 & \pm 40 \\
$\mathbf{N}$ & $\mathrm{NA}$ & \pm 7.1 & \pm 5.0 & \pm 3.6 \\
$\mathrm{Ti}$ & 63.4 & \pm 10 & \pm 21.8 & \pm 49.6 \\
$\mathbf{O}$ & 34.6 & \pm 8.3 & \pm 12 & \pm 2.9 \\
$\mathrm{Cl}$ & $\mathrm{NA}$ & \pm 1.6 & \pm 2.1 & \pm 3.7 \\
C to Ti ratio & $\mathrm{NA}$ & $7: 1$ & $3: 1$ & $1: 1$ \\
\hline
\end{tabular}

Therefore, the detected $\mathrm{C}-\mathrm{N}, \mathrm{C}=\mathrm{N}$ and $\mathrm{C}=\mathrm{C}$ bonds resulted from chain conjugation whereby $\mathrm{C}=\mathrm{C}$ bonds were formed during the tautomerisation of the cyclised product [34]. Likewise, the $\mathrm{C}=\mathrm{O}$ stretching from DMF solvent trapped in polymer certainly evaporated early on during pyrolysis of $\mathrm{C}-\mathrm{N}-\mathrm{TiO}_{2}$ at $350^{\circ} \mathrm{C}$, recalling that the boiling point of $\mathrm{DMF}$ is estimated to be around $153^{\circ} \mathrm{C}$ according to Darányi et al. [33], as a clear weight loss was evident below $130^{\circ} \mathrm{C}$. 


\subsection{Electron Energy Loss Spectroscopy}

The presence of bonding between $\mathrm{C}, \mathrm{N}$ and Ti in the synthesised catalysts was investigated by electron energy-loss spectroscopy (EELS) plotted in Figure 3.
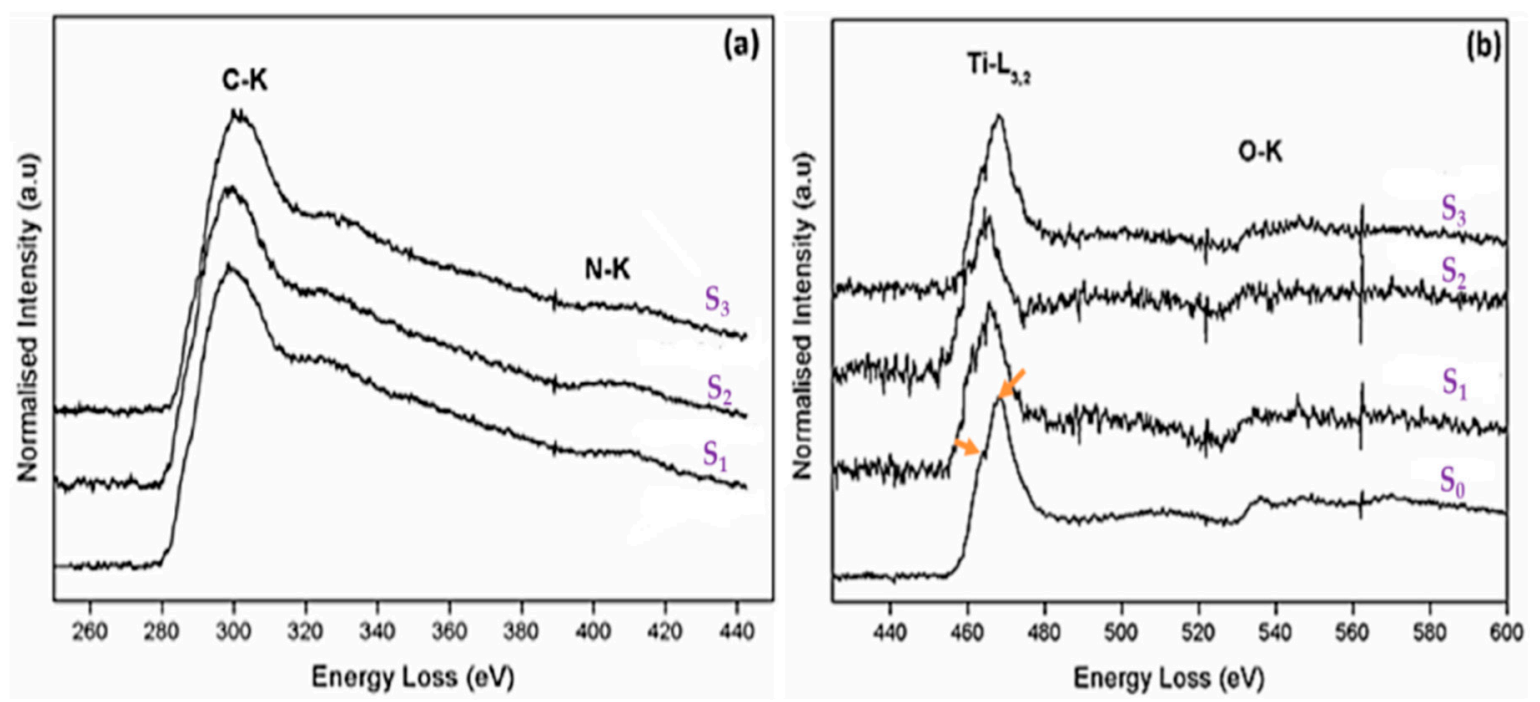

Figure 3. Electron energy-loss spectra of (a) carbon $\mathrm{K}$ edge and nitrogen $\mathrm{K}$ edge line profiles and (b) titanium $\mathrm{L}_{3,2}$ and oxygen $\mathrm{K}$ edge line profiles of the different catalysts synthesized by sol-gel method, and pyrolysed at $350{ }^{\circ} \mathrm{C}$ at $50{ }^{\circ} \mathrm{C} / \mathrm{min}$ ramping rate for different times $\left(\mathrm{S}_{0}=\right.$ Degussa $\mathrm{TiO}_{2}$; $\left.\mathrm{S}_{1}=\mathrm{C}-\mathrm{N}-\mathrm{TiO}_{2} 105 \mathrm{~min} ; \mathrm{S}_{1}=\mathrm{C}-\mathrm{N}-\mathrm{TiO}_{2} 105 \mathrm{~min} ; \mathrm{S}_{2}=\mathrm{C}-\mathrm{N}-\mathrm{TiO}_{2} 120 \mathrm{~min} ; \mathrm{S}_{3}=\mathrm{C}-\mathrm{N}-\mathrm{TiO}_{2} 135 \mathrm{~min}\right)$.

Figure 3a confirms the presence of both carbon (K edge onset detected at $284 \mathrm{eV}$ ) and nitrogen (K edge at $404 \mathrm{eV}$ ) present in all three doped specimens. Figure $3 \mathrm{~b}$ shows the titanium $\mathrm{L}_{3,2}$ line profile of the doped specimens against that of the undoped Degussa $\mathrm{TiO}_{2}$. From the Degussa line profile, the common crystal field splitting from the predominantly rutile crystal structure is indicated by the arrows between 460 and $480 \mathrm{eV}$.

The hump on the lower $\mathrm{eV}$ side is the $\mathrm{L}_{3}$ peak, which originates from electron transitions from the inner $2 p_{3 / 2}$ orbitals to empty $3 d$ orbitals of the Ti metal. The $L_{2}$ edge, on the higher eV side, originates from $2 \mathrm{p}_{1 / 2} \rightarrow 3 \mathrm{~d}$ electron transitions. In the case of Ti oxides, the near-edge structures found in the $\mathrm{L}_{3,2}$ edges mainly reflect the covalent bonding states resulting from direct and/or indirect interactions between $\mathrm{O}$ and $\mathrm{Ti}$ atoms. As such, a study of this edge structure, i.e., its change in crystal field splitting and or shifting of peak position, can give an idea of the introduction of foreign atoms into the $\mathrm{TiO}_{2}$ lattice, i.e., doping.

From Figure 3b, it can be seen that with an increase in synthesis time, there is a slight shift in the $\mathrm{Ti} \mathrm{L}_{3,2}$ line shape position compared to that of the undoped Degussa $\mathrm{TiO}_{2}$. This was further confirmed by the splitting of the $\mathrm{L}_{3,2}$ peak located between 460 and $480 \mathrm{eV}$ with $\mathrm{TiO}_{2}$ Degussa into individual $\mathrm{L}_{3}$ and $\mathrm{L}_{2}$ humps at $462 \mathrm{eV}$ in Figure $3 \mathrm{~b}$ that were indiscernible in the case of the $\mathrm{S}_{1}$ or $\mathrm{S}_{2}$ samples, but well present at $470 \mathrm{eV}$ in the $\mathrm{S}_{3}$ sample.

\subsection{XPS Analysis of $\mathrm{C}-\mathrm{N}-\mathrm{TiO}_{2}$ Catalysts}

Besides EELS, XPS analysis was carried out to verify the surface composition and chemical states of $\mathrm{C}-\mathrm{N}-\mathrm{TiO}_{2}$ nano materials calcined at $350{ }^{\circ} \mathrm{C}$ for $105 \mathrm{~min}\left(\mathrm{~S}_{1}\right), 120 \mathrm{~min}\left(\mathrm{~S}_{2}\right)$ or $135 \mathrm{~min}\left(\mathrm{~S}_{3}\right)$. The XPS survey spectra in Figure 4 a shows that Ti $3 p, T i 3 s, C 1 s, N$ 1s, Ti 2p, O 1 s and $\mathrm{O}_{\mathrm{KLL}}$ were obtained from each of the calcined $\mathrm{C}-\mathrm{N}-\mathrm{TiO}_{2}$ catalysts. High-resolution XPS spectra in Figure $4 \mathrm{~b}$ shows $\mathrm{C} 1 \mathrm{~s}$ peaks for three catalysts were $282.6 \mathrm{eV}$ for $\mathrm{S}_{1}, 283.2 \mathrm{eV}$ for $\mathrm{S}_{2}$ and $283 \mathrm{eV}$ for $\mathrm{S}_{3}$ and corresponded to Ti-C in $\mathrm{C}-\mathrm{N}-\mathrm{TiO}_{2}$ catalysts. The carbon atom was substituted for the oxygen atom in the lattice of $\mathrm{TiO}_{2}$ to form Ti-C $[35,36]$ in which the surface amount of Ti-C was increased substantially by increasing 
pyrolysis time from; $9.7 \%$ for $S_{1}$ to $42.0 \%$ for $S_{2}$ and $48.3 \%$ for $S_{3}$, respectively. This may be due to the diffusion of carbon from the bulk to the surface when increasing the pyrolysis holding time. The binding energy at $284.6 \mathrm{eV}$ attributed to $\mathrm{C}-\mathrm{C} / \mathrm{C}-\mathrm{H}$ mainly derived from the decomposition of PAN shown in Figure $3 \mathrm{~b}$ and $\mathrm{NH}_{4} \mathrm{NO}_{3}$ as well as from so-called adventitious carbon [37]. The peaks at $286.4 \mathrm{eV}$ for $\mathrm{S}_{1}, 286.3 \mathrm{eV}$ for $\mathrm{S}_{2}$ and $286.5 \mathrm{eV}$ for $\mathrm{S}_{3}$ could be assigned to the $\mathrm{C}=\mathrm{N}$ functional groups obtained from the decomposition of PAN and $\mathrm{NH}_{4} \mathrm{NO}_{3}$ [38]. The deconvolution of $\mathrm{N} 1$ s peak resulted in two distinct peaks as shown in Figure 4c. The peak centred at $397.3 \mathrm{eV}$ for $\mathrm{S}_{1}, 397.1 \mathrm{eV}$ for $\mathrm{S}_{2}$ and $396.7 \mathrm{eV}$ for $\mathrm{S}_{3}$ could be from $\mathrm{N}$ atoms in O-Ti-N linkages [39]. The other peak at $399.1 \mathrm{eV}$ for $\mathrm{S}_{1}$, $398.5 \mathrm{eV}$ for $\mathrm{S}_{2}$ and $398.3 \mathrm{eV}$ for $\mathrm{S}_{3}$ were from $\mathrm{C}=\mathrm{N}-\mathrm{C}$ as in pyridine $\mathrm{N}$ [39].
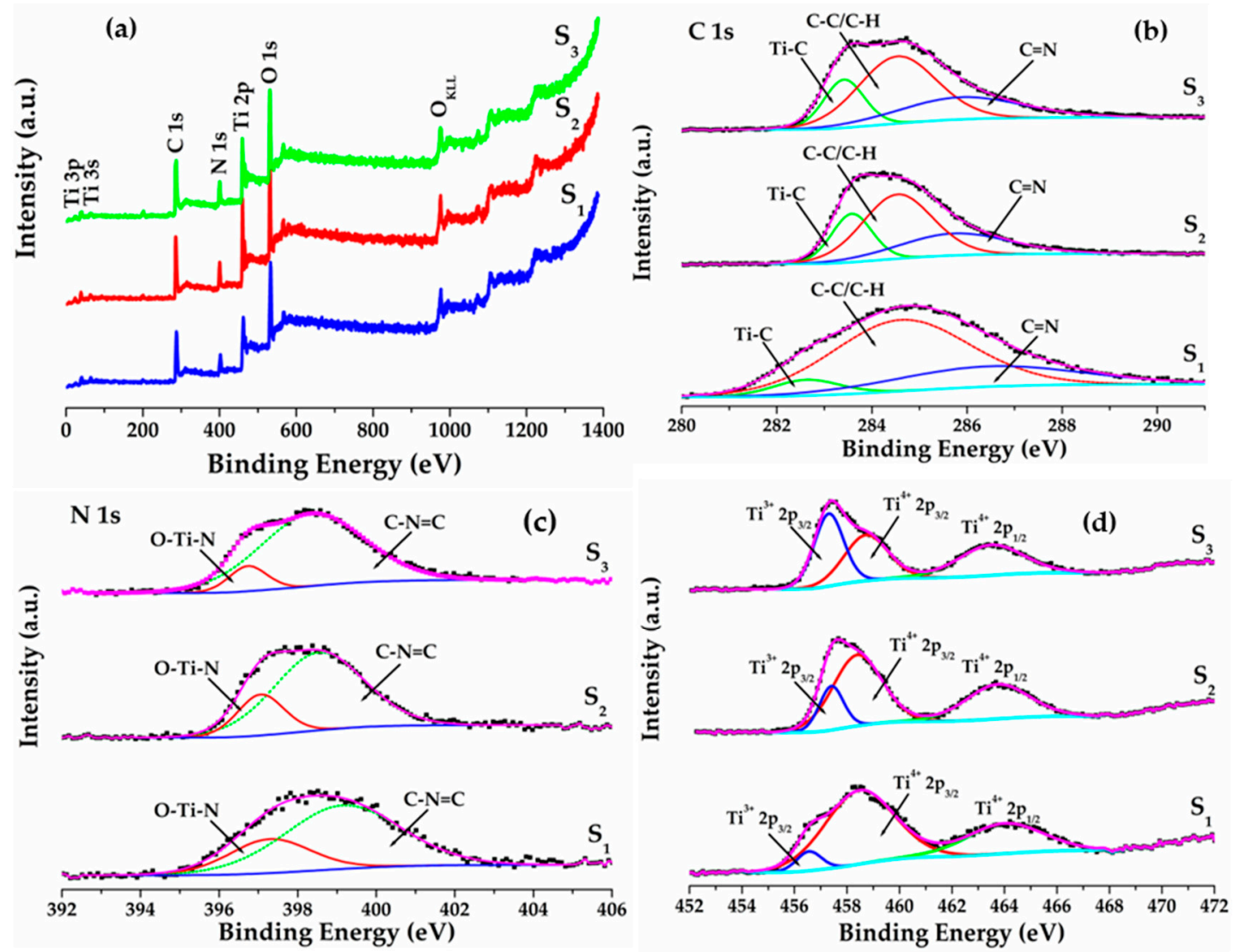

Figure 4. (a) The XPS survey spectra, (b) high-resolution C 1s, (c) high-resolution $\mathrm{N} 1 \mathrm{~s}$ and (d) high-resolution $\mathrm{Ti} 2 \mathrm{p}$ for $\mathrm{C}-\mathrm{N}-\mathrm{TiO}_{2}$ catalysts calcined at $350{ }^{\circ} \mathrm{C}$ for $105 \mathrm{~min}, 120 \mathrm{~min}$ and $130 \mathrm{~min}$.

The high-resolution spectra in Figure $4 \mathrm{~d}$ demonstrated $\mathrm{Ti} 2 \mathrm{p}$ peaks for $\mathrm{C}-\mathrm{N}-\mathrm{TiO}_{2}$ catalysts calcined at different temperatures. The peaks at $458.3 \mathrm{eV}$ and $464.1 \mathrm{eV}$ for $\mathrm{S}_{1}$ could be assigned as Ti $2 \mathrm{p}_{3 / 2}$ and Ti $2 \mathrm{p}_{1 / 2}$ with a spin orbit splitting of $5.8 \mathrm{eV}$ which was in good agreement with the binding energy separation value of stoichiometric $\mathrm{TiO}_{2}[40,41]$. The Ti $2 p$ peaks for catalysts $S_{2}$ and $\mathrm{S}_{3}$ exhibited the binding energies shift toward lower values as Ti $2 \mathrm{p}_{3 / 2}$ at $457.7 \mathrm{eV}$ and Ti $2 \mathrm{p}_{1 / 2}$ at $463.7 \mathrm{eV}$ and $\mathrm{Ti}$ $2 \mathrm{p}_{3 / 2}$ at $457.4 \mathrm{eV}$ and Ti $2 \mathrm{p}_{1 / 2}$ at $463.5 \mathrm{eV}$ with a spin orbit splitting of $6 \mathrm{eV}$ and $6.1 \mathrm{eV}$, respectively. The reduction in Ti $2 p$ binding energies toward lower values when increasing the pyrolysis holding time was due to increase in formation of Ti-C (confirmed by Ti-C component in $\mathrm{C}$ 1s high resolution) and reduction of $\mathrm{Ti}^{4+}$ to $\mathrm{Ti}^{3+}$ by accepting electrons and partial replacement of $\mathrm{O}^{2-}$ with $\mathrm{N}^{3-}$ to form Ti-N bonds [41]. 
2.6. Scanning Electron Microscopy and Energy-Dispersive Spectroscopy of $\mathrm{C}-\mathrm{N}-\mathrm{TiO} \mathrm{O}_{2}$ Pyrolysed at Different Holding Times

Figure 5 presents SEM micrographs of pure $\mathrm{TiO}_{2}$ compared with the co-doped $\mathrm{C}-\mathrm{N}-\mathrm{TiO}_{2}$ nano composites synthesised by the sol-gel method and calcined at $350{ }^{\circ} \mathrm{C}$ at $50{ }^{\circ} \mathrm{C} / \mathrm{min}$ for 105,120 or 135 min holding time.
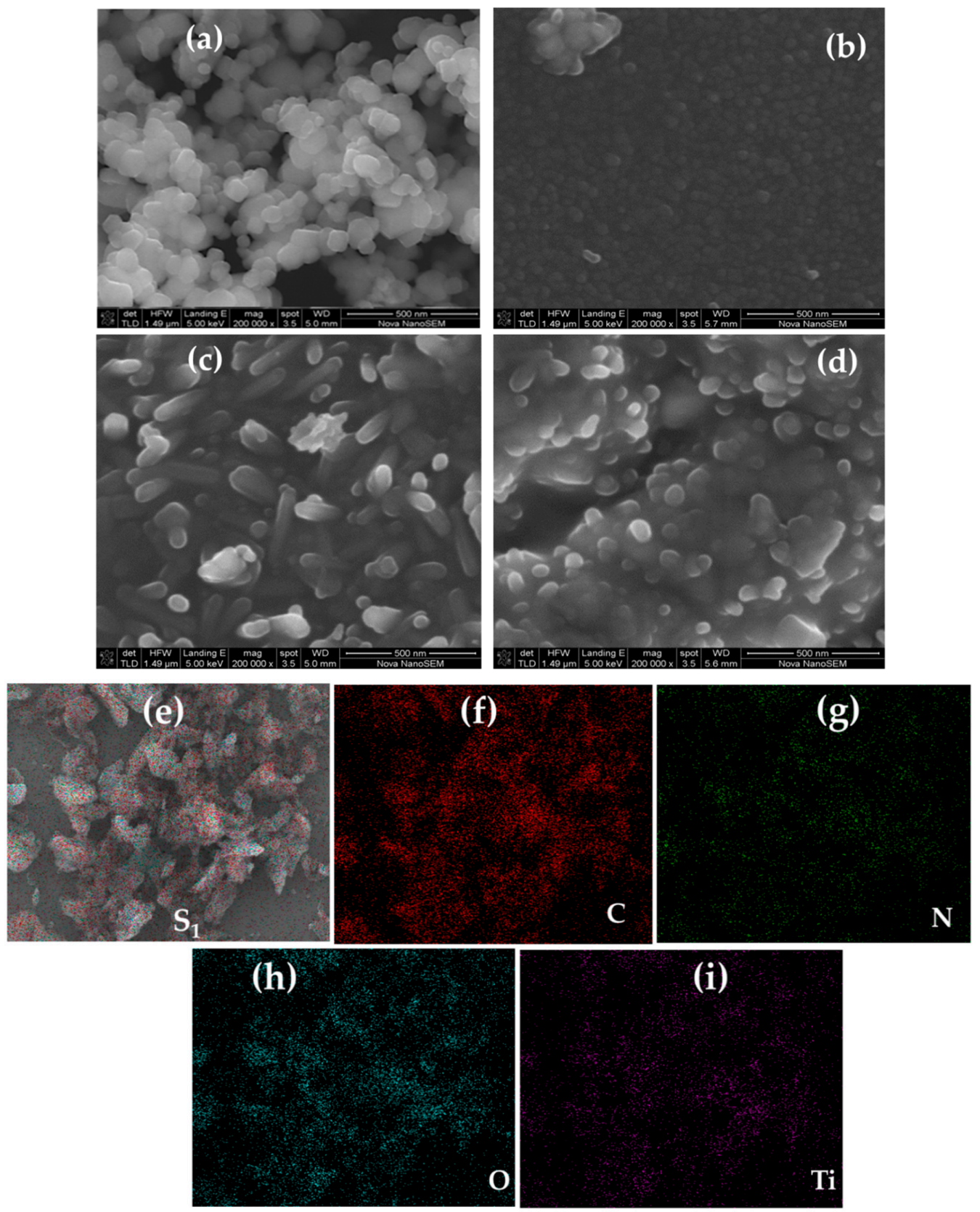

Figure 5. (a-d) Scanning electron microscopy (SEM) of (a) pure Degussa and $\mathrm{C}-\mathrm{N}-\mathrm{TiO}_{2}$ pyrolysed at $350{ }^{\circ} \mathrm{C}$ at a ramping rate of $50{ }^{\circ} \mathrm{C} / \mathrm{min}$ at different holding times: (b) $105 \mathrm{~min}$, (c) $120 \mathrm{~min}$ and (d) $135 \mathrm{~min}$, and energy-dispersive X-ray spectroscopy (EDS) elemental mapping (e-i) of selected $\mathrm{C}-\mathrm{N}-\mathrm{TiO}_{2}$ pyrolysed for $105 \mathrm{~min}$.

The SEM photograph in Figure 5a is for Degussa P25 showing individual $21 \mathrm{~nm}$ spherical crystallites. The SEM image of $\mathrm{C}-\mathrm{N}-\mathrm{TiO}_{2}$ pyrolysed for different holding times, presents an agglomerated morphological aspect showing residual PAN whereas fine powder particles were observed for pure $\mathrm{TiO}_{2}$ Degussa in Figure 5a. Figure $4 \mathrm{~b}$ shows the formation of small spherical and 
cubic granular-shaped $\mathrm{C}-\mathrm{N}-\mathrm{TiO}_{2}$ nano crystallites pyrolysed for $105 \mathrm{~min}$ which were well distributed in a carbon matrix as shown by TGA and XPS and had a size of $5.5 \mathrm{~nm}$ compared to the randomly dispersed longitudinal spindle-and rod shaped crystals $(6.3 \mathrm{~nm})$, in Figure $5 \mathrm{c}$ and condensed agglomerated forms $(6.4 \mathrm{~nm})$, in Figure $5 \mathrm{~d}$ when pyrolysis time was increased to 120 or $135 \mathrm{~min}$, respectively. The SEM also showed that the $\mathrm{TiO}_{2}$ crystal sizes were larger than determined by the Scherrer equation indicating poly crystalline agglomerates of $\mathrm{TiO}_{2}$ with well-developed particulate structures of sizes between 5 and $40 \mathrm{~nm}$ determined using ImageJ software and set in a matrix of carbon residues derived from the PAN precursor [42,43]. The EDS mapping micrographs in Figure 5e demonstrate that C, N, O and Ti were all present and well dispersed in the synthesised $\mathrm{C}-\mathrm{N}-\mathrm{TiO}_{2}$ nano composites.

Similar morphological changes were noticed by Tijani et al. [20] and Cheng et al. [19] during the synthesis of $\mathrm{C}-\mathrm{TiO}_{2}$ and $\mathrm{N}-\mathrm{TiO}_{2}$ nano catalysts by different methods. These authors reported that isolated $\mathrm{C}$ and $\mathrm{N}$ dopants in their substitutional bonding forms $\mathrm{C}-\mathrm{O}-\mathrm{Ti}-\mathrm{O}$ and $\mathrm{N}-\mathrm{Ti}-\mathrm{O}$ in forbidden bands of $\mathrm{TiO}_{2}$ lattice became unstable when increasing pyrolysis time.

During pyrolysis in $\mathrm{N}_{2}$ the PAN used as carbon source in this study degraded and its partially pyrolysed carbon residues are still very much evident as the matrix around each $\mathrm{TiO}_{2}$ crystal, as was observed in elemental EDS mapping shown in Figure 5e and HRTEM in Figure 6. At longer times, less of the carbon residue remained compared to $\mathrm{TiO}_{2}$ Degussa that showed no mass loss around $130^{\circ} \mathrm{C}$, as shown by TGA with about 8,10 or $14 \%$ mass loss noted for $S_{1}, S_{2}$ and $S_{3}$, respectively. Thus, when increasing pyrolysis holding time at $350^{\circ} \mathrm{C}$ from 105 to 120 or $135 \mathrm{~min}$, PAN decomposes into $\mathrm{C}$ and $\mathrm{N}$ in the $\mathrm{TiO}_{2}$ matrix. This resulted in random recombination with $\mathrm{O}$ giving off toxic gases such as $\mathrm{NO}, \mathrm{NO}_{2}, \mathrm{CO}, \mathrm{CN}$ as supported by FTIR and a total mass loss of $6 \%$ by TGA analysis. The $\mathrm{NH}_{4} \mathrm{NO}_{3}$ dosed during sol-gel preparation contributed as $\mathrm{N}$ source $\left(\mathrm{NH}_{4}{ }^{+}\right)$while nitrates could have evaporated as $\mathrm{NO}_{2}$ and related gases.

Thus, by increasing the pyrolysis time, we reduced the amount of PAN residues due to the diffusion of incorporated $\mathrm{C}$ and $\mathrm{N}$ probably to the surface of the semiconductor photo catalyst. Consequently, an analysis of the relative concentrations of $\mathrm{C}, \mathrm{N}$ and other elements in the catalysts was assessed to compliment the claims discussed in FTIR, TGA and SEM analysis.

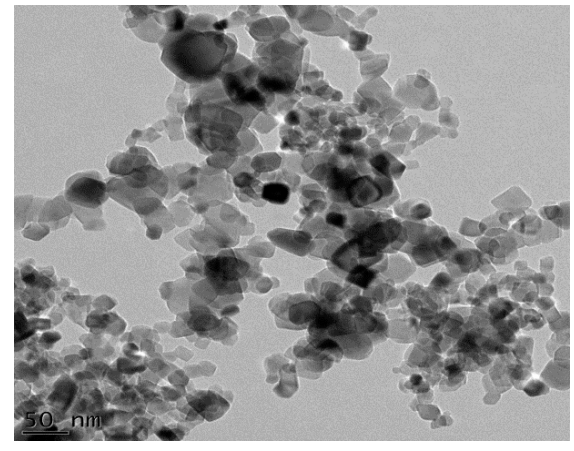

(a)

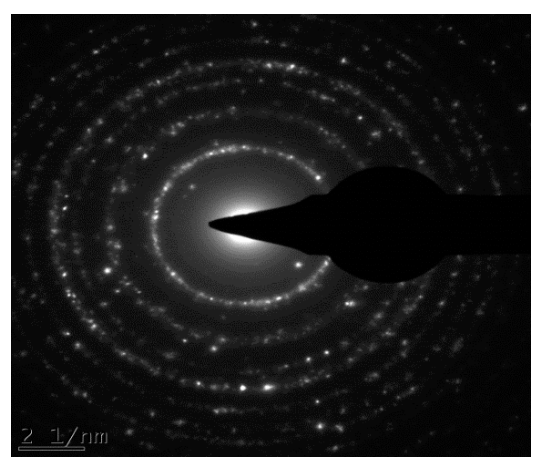

(c)

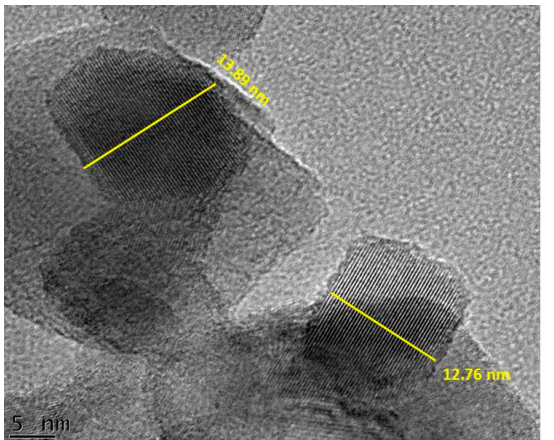

(b)

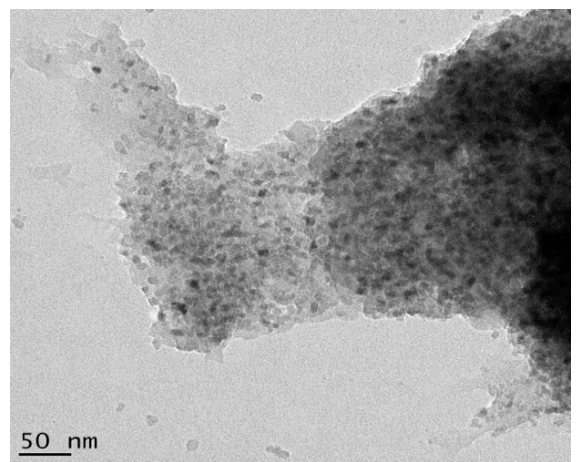

(d)

Figure 6. Cont. 


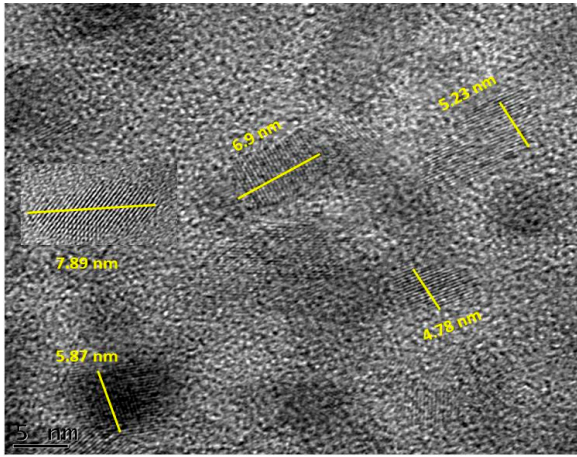

(e)

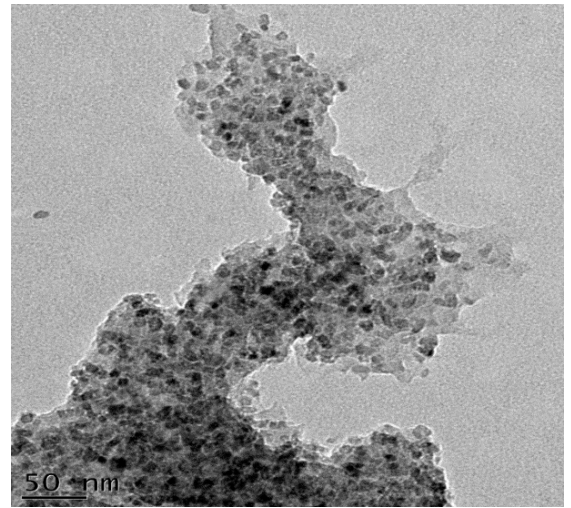

(g)

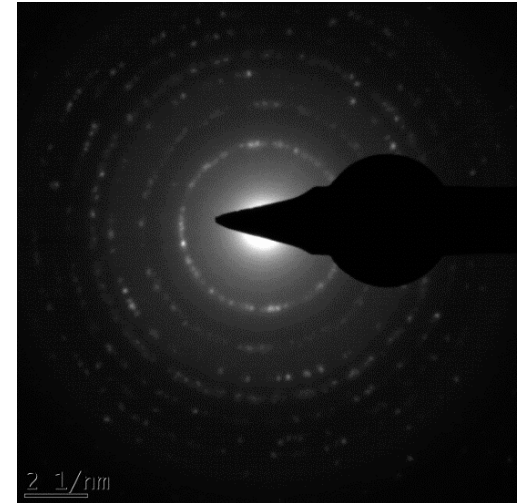

(i)

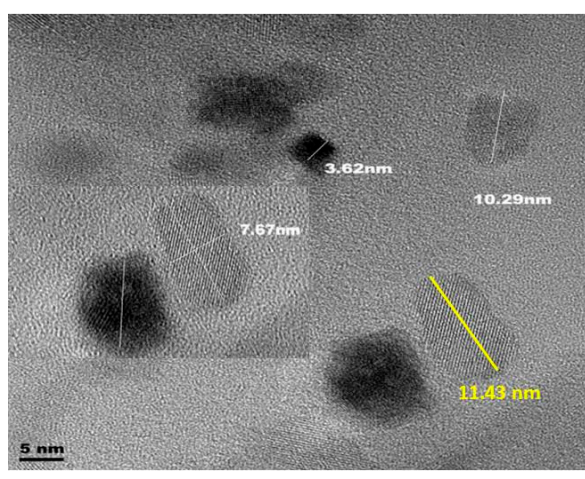

(k)

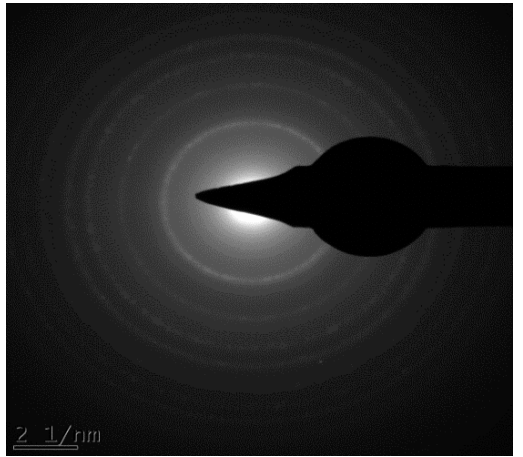

(f)

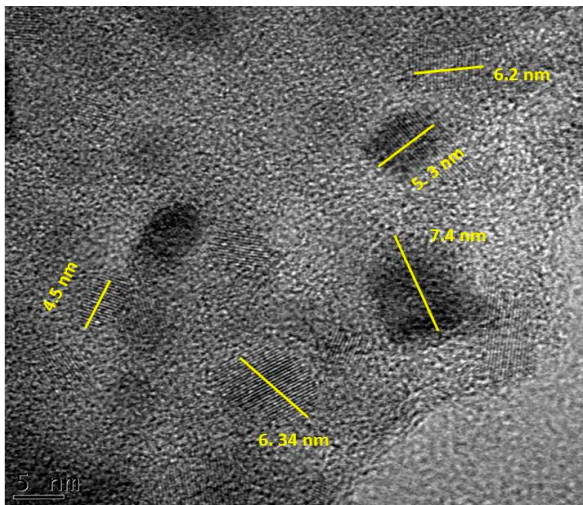

(h)

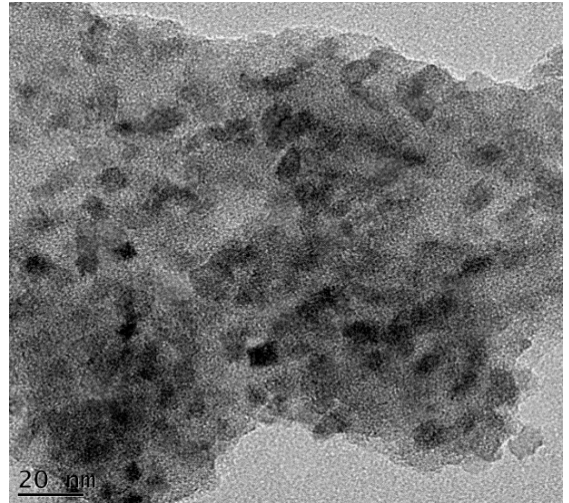

(j)

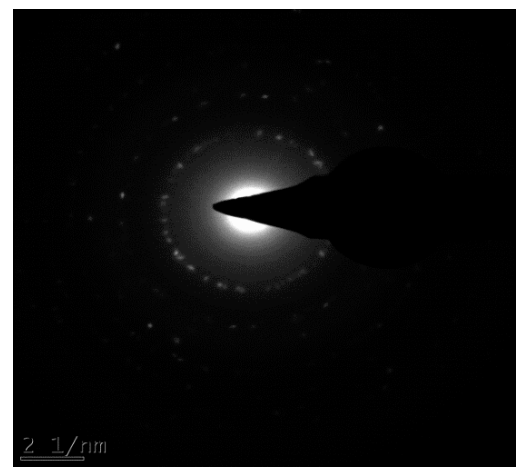

(1)

Figure 6. Bright-field micrographs and SAED patterns of (a-c) Degussa $\mathrm{TiO}_{2}\left(\mathrm{~S}_{0}\right) ;(\mathbf{d}-\mathbf{f}) 105 \mathrm{~min}$ $\mathrm{C}-\mathrm{N}-\mathrm{TiO}_{2}\left(\mathrm{~S}_{1}\right) ;(\mathrm{g}-\mathrm{i}) 120 \mathrm{~min} \mathrm{C}-\mathrm{N}-\mathrm{TiO}_{2}\left(\mathrm{~S}_{2}\right) ;(\mathrm{j}-1) 135 \mathrm{~min} \mathrm{C}-\mathrm{N}-\mathrm{TiO}_{2}\left(\mathrm{~S}_{3}\right)$ pyrolysed at $350{ }^{\circ} \mathrm{C}$ at $50{ }^{\circ} \mathrm{C} /$ min ramping. 


\subsection{Transmission Electron Microscopy and Thin Film Energy-Dispersive Spectroscopy of the Synthesised} $\mathrm{C}-\mathrm{N}-\mathrm{TiO}_{2}$ Nano-Composites

The FEG-TEM analysis coupled with EDS spot analysis (TEM-EDS) of small selected areas were used to determine the elemental composition of the prepared nano composites. This allowed the determination of the relative concentrations of $\mathrm{C}, \mathrm{N}$ and other elements in the catalysts to compliment the claims discussed in FTIR, TGA and SEM analysis.

Although the sensitivity of SEM-EDS was very low for $\mathrm{N}$ detection, the small area approach during TEM-EDS allowed for greater sensitivity as shown in Table 3, with weight percentage of $\mathrm{C}$ $(72.32 \%), \mathrm{Ti}(10.55 \%), \mathrm{N}(7.1 \%)$ and $\mathrm{O}(8.26 \%)$ showing that $\mathrm{C}$ and $\mathrm{N}$ were present in the $\mathrm{TiO}_{2}$ compound after $105 \mathrm{~min}$ of holding time. While chlorine impurities (1.66\%) were certainly derived from the Ti precursor $\left(\mathrm{TiCl}_{4}\right)$ used during sol-gel preparation, $\mathrm{Cu}$ resulted from the copper grid used to support samples during TEM analysis. The $\mathrm{C}$ to Ti ratios in Table 3 show that a slight change in holding time causes such a difference in the carbon matrix due to the instability of $\mathrm{C}$ in PAN heated at $350{ }^{\circ} \mathrm{C}$. Moreover, the huge amount of carbon measured by TEM-EDS in Table 3 probably includes residues of degraded PAN gluing the crystals together; on the other hand, this could also result from $C$ diffused to the surface of $\mathrm{C}-\mathrm{N}-\mathrm{TiO}_{2}$ when PAN decomposed during the calcination process.

As expected, it could be noticed that increasing pyrolysis time resulted in a decrease of the $\mathrm{C}$ content and the concomitant increase of Ti content. This is proven by the EDS weight $\%$ results showing the decline in carbon content from 72, 64.0 to 40 after 105, 120 or 135 min of pyrolysis, while that of $\mathrm{Ti}$ content increased from $10.55 \%, 21.86 \%$ to $49.65 \%$, probably due to the carbon loss during pyrolysis. In addition, it should be mentioned that as PAN has $\mathrm{N}$ in its structure; $\mathrm{N}$ was already present before $\mathrm{NH}_{4} \mathrm{NO}_{3}$ addition; therefore, this explains the increase in $\mathrm{N}$ content observed in Table 3.

Furthermore, nitrogen content decreased from $7 \%$ to $3 \%$ during the pyrolysis process. Therefore, a longer pyrolysis time induced volatilisation of the $\mathrm{C}$ and $\mathrm{N}$ introduced upon the $\mathrm{TiO}_{2}$ matrix by use of $\mathrm{PAN}$ and $\mathrm{NH}_{4} \mathrm{NO}_{3}$ and led to morphological changes of the synthesised nanoparticles as shown by SEM analysis in Figure 5.

\subsection{Transmission Electron Microscopy and Selected Area Electron Diffraction Analysis of $\mathrm{TiO}_{2}$ Degussa and $\mathrm{C}-\mathrm{N}-\mathrm{TiO}_{2}$ Nanoparticles}

The $\mathrm{C}$ and $\mathrm{N}$ forming a matrix around and upon the $\mathrm{TiO}_{2}$ of $\mathrm{C}-\mathrm{N}-\mathrm{TiO}_{2}$ pyrolysed for different holding times was assessed by TEM coupled with selected area diffraction patterns (TEM-SAED) as shown in Figure 6. Figure $6 \mathrm{c}, \mathrm{f}, \mathrm{i}, \mathrm{l}$ presents the SAED patterns of $\mathrm{S}_{0}$ (Figure $6 \mathrm{c}$ ) and those of $\mathrm{C}-\mathrm{N}-\mathrm{TiO}_{2}$ nano catalysts $S_{1}$ (Figure $6 \mathrm{~d}-\mathrm{f}$ ), $S_{2}$ (Figure $6 \mathrm{~g}-\mathrm{i}$ ) and $\mathrm{S}_{3}$ (Figure $6 \mathrm{j}-1$ ) pyrolysed under nitrogen gas at $350{ }^{\circ} \mathrm{C}$ at a ramping rate of $50^{\circ} \mathrm{C} / \mathrm{min}$.

The TEM micrographs in Figure 6a showed the Degussa $\mathrm{P} 25 \mathrm{TiO}_{2}$ crystals (bright crystals) and its SAED pattern (5c). While in Figure 6d,g,j the TEM images showed that $C$ and $N$ impurities were well distributed throughout the $\mathrm{TiO}_{2}$ matrix. These observations were also supported by the $\mathrm{TiO}_{2}$ crystals embedded in the carbon matrix surrounding the $\mathrm{TiO}_{2}$ catalysts as shown in Figure 6e,h,k. The bright small reflections in the polymorphic rings observed in these images confirmed the polycrystalline nature of the $\mathrm{TiO}_{2}$ nanoparticles.

The bright reflections on the spherical lines corresponded to the crystal plane (110) could be ascribed to distinctive $\mathrm{C}-\mathrm{N}-\mathrm{TiO}_{2}$ nano crystals mostly in pure mineral anatase phase. However, the crystal lattice reflections are brighter in the $\mathrm{S}_{0}$ sample compared to those in Figure 6f,i,l probably due to the small randomly oriented nanoscale $\mathrm{TiO}_{2}$ domains in agglomerated particles as can be deduced by comparing Scherrer equation estimations and SEM or TEM images.

From the SAED, it is also possible to account for the graphitic carbon content as diffuse rings were evident, particularly in Figure 6f in which the sample had the highest carbon content [44]. 


\subsection{UV-Vis Spectroscopy Analysis, Determination of the Nano Catalyst Band Gap}

The outcomes exhibited in Table 4 indicated that upon $\mathrm{C}$ and $\mathrm{N}$ deposition, the $3.2 \mathrm{eV}$ absorption band gap of pure anatase/Degussa $\mathrm{TiO}_{2}$ was narrowed to $2.67 \mathrm{eV}, 3.10$ and $3.17 \mathrm{eV}$ when pyrolysis time was altered from 105, 120 to $135 \mathrm{~min}$, correspondingly showing how accurately the pyrolysis time allows band gap tailoring. The wavelengths and the approximated band gaps are recorded in Table 4 and plotted in Figure $7 \mathrm{~b}$.

Table 4. Effect of pyrolysis time under $\mathrm{N}_{2}$ gas at $350{ }^{\circ} \mathrm{C}$ and ramping rate of $50^{\circ} \mathrm{C} / \mathrm{min}$ on the band gap of the synthesised $\mathrm{C}-\mathrm{N}-\mathrm{TiO}_{2}$ nano catalysts $\left(\mathrm{S}_{0}=\right.$ with Degussa $\mathrm{TiO}_{2} ; \mathrm{S}_{1}=\mathrm{C}-\mathrm{N}-\mathrm{TiO}_{2} 105$ min; $\mathrm{S}_{2}=\mathrm{C}-\mathrm{N}-\mathrm{TiO}_{2} 120 \mathrm{~min}$ and $\left.\mathrm{S}_{3}=\mathrm{C}-\mathrm{N}-\mathrm{TiO}_{2} 135 \mathrm{~min}\right)$.

\begin{tabular}{cccc}
\hline Photo Catalysts & Pyrolysis Holding Time (min) & UV-Vis Absorption Wavelength (nm) & Band Gap (eV) \\
\hline$S_{0}$ & NA & 408 & 3.2 \\
$S_{1}$ & 105 & 462 & 2.67 \\
$S_{2}$ & 120 & 393 & 3.10 \\
$S_{3}$ & 135 & 333 & 3.17 \\
\hline
\end{tabular}
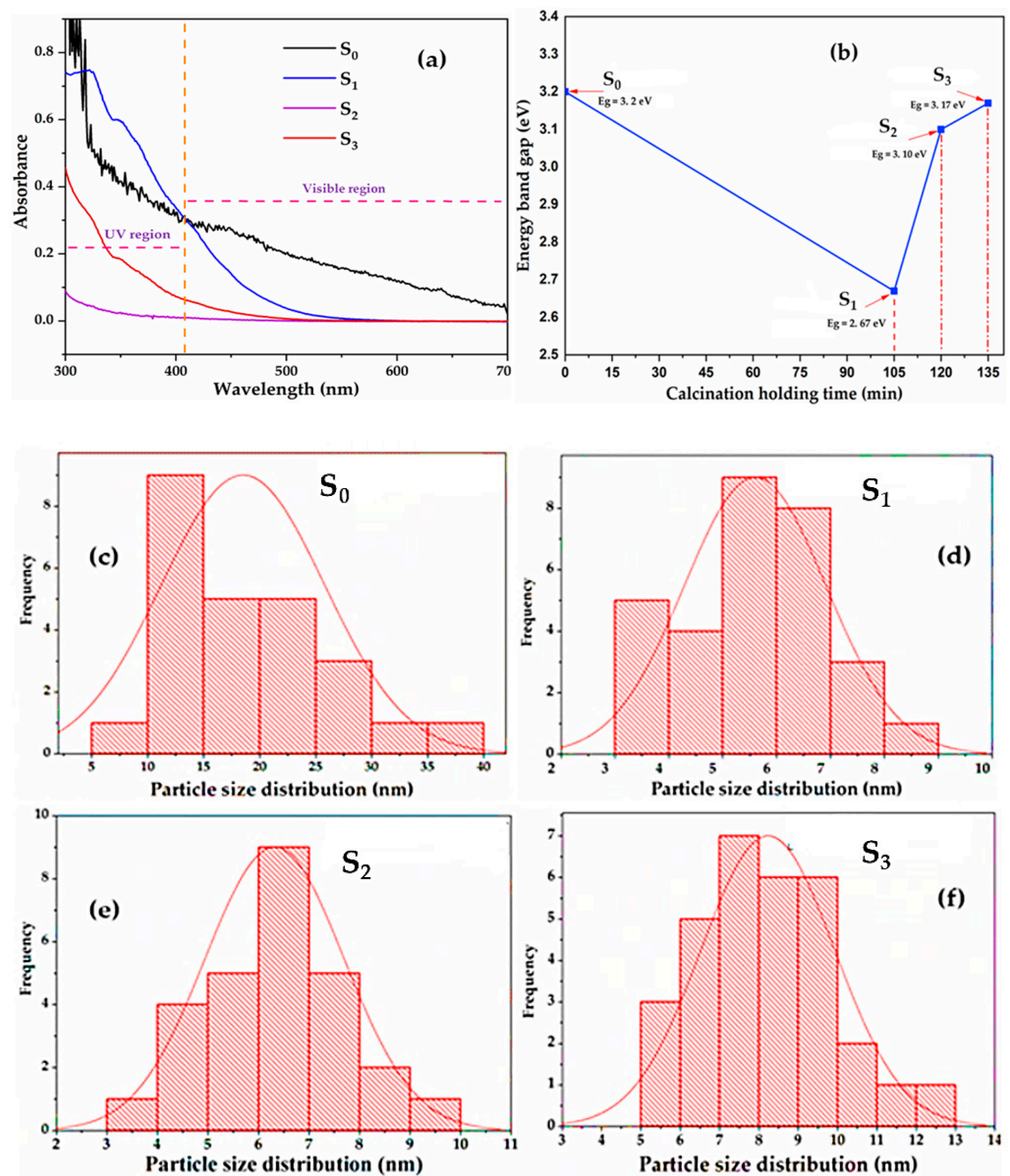

Figure 7. Effect of calcination holding time ( $\min )$ on band gap $(\mathbf{a}, \mathbf{b})$ and particle distribution of the Degussa $\mathrm{TiO}_{2}$ (c) compared to the synthesised $\mathrm{C}-\mathrm{N}-\mathrm{TiO}_{2}$ nano composites pyrolysed at $350{ }^{\circ} \mathrm{C}$ for 105 (d); 120 (e) and135 (f) minutes $\left(\mathrm{S}_{0}=\right.$ with Degussa $\mathrm{TiO}_{2} ; \mathrm{S}_{1}=\mathrm{C}-\mathrm{N}-\mathrm{TiO}_{2} 105 \mathrm{~min} ; \mathrm{S}_{2}=\mathrm{C}-\mathrm{N}-\mathrm{TiO}_{2}$ $120 \mathrm{~min}$ and $\left.\mathrm{S}_{3}=\mathrm{C}-\mathrm{N}-\mathrm{TiO}_{2} 135 \mathrm{~min}\right)$.

The results in Table 4 and Figure $7 \mathrm{a}, \mathrm{b}$ showed that $\mathrm{C}-\mathrm{N}-\mathrm{TiO}_{2}$ catalysts $\mathrm{S}_{1}$ had a band gap of $2.67 \mathrm{eV}$, smaller than 3.10 and $3.17 \mathrm{eV}$ obtained for $\mathrm{S}_{2}$ and $\mathrm{S}_{3}$ when pyrolysis time was increased to 
$120 \mathrm{~min}$ and $135 \mathrm{~min}$. The UV-Vis wavelengths (from Figure 7a) showed that $\mathrm{S}_{0}$ absorbed at $408 \mathrm{~nm}$ and $S_{1}$ in the visible region at approximately $462 \mathrm{~nm} ; S_{2}$ and $S_{3}$ absorbed in the UV region at 393 and $333 \mathrm{~nm}$, respectively.

The slight decrease of wavelength and small increase of the computed band gap of the $\mathrm{C}-\mathrm{N}-\mathrm{TiO}_{2}$ nano catalysts obtained after longer pyrolysis time was correlated with the amount of $\mathrm{C}$ and $\mathrm{N}$ remaining after evaporation during the pyrolysis process as confirmed by FTIR and TGA analysis. All C-N-TiO 2 nano catalysts presented band gap values smaller than the one of $\mathrm{S}_{0}(3.2 \mathrm{eV})$ as presented in Table 4 and highlighted by Carp et al. [45], Li et al. [46] and Gilmour and Ray [47].

The reduction of the typical $\mathrm{TiO}_{2}$ band gap from $3.2 \mathrm{eV}$ to $2.67 \mathrm{eV}$ after $105 \mathrm{~min}$ of pyrolysis was likely due to the presence of oxygen vacancies that acted like electron-donors in the valence band of the photo catalyst and hence accumulating more layers (microstates) with new electronic properties which further reduced its energy absorption gap [15,48].

In this study, concentrations of PAN and $\mathrm{NH}_{4} \mathrm{NO}_{3}$ precursors of $\mathrm{C}$ and $\mathrm{N}$ were kept constant during synthesis of $\mathrm{C}-\mathrm{N}-\mathrm{TiO}_{2}$ co-doped nano catalyst. The increase of the band gap from 2.67 to 3.10 and $3.17 \mathrm{eV}$ when increasing pyrolysis time suggested that the stability of $\mathrm{C}$ and $\mathrm{N}$ upon and $\mathrm{inTiO}_{2}$ structural lattice depended on the degree of volatilisation of these two substituents as previously shown by FTIR. This inferred that the engineered $\mathrm{C}-\mathrm{N}-\mathrm{TiO}_{2}$ nano particles are stable at a specific pyrolysis holding time; an increase of holding time may lead to changes in their band gap, recombination rate of electron hole pairs, morphology, and particle size as early reported by Tijani et al. [49].

Thus, to achieve the maximum desired catalytic properties, of the $\mathrm{C}-\mathrm{N}-\mathrm{TiO}_{2}$-based materials via the sol-gel pyrolysis protocol, one should optimise and carefully control the holding time during the pyrolysis process. To our knowledge, most of the studies published in the literature have not observed this condition when using PAN as a $\mathrm{C}$ precursor.

\subsection{Particles Size Distribution of $\mathrm{TiO}_{2}$ Degussa and the Synthesised $\mathrm{C}-\mathrm{N}-\mathrm{TiO} \mathrm{O}_{2}$ Nano Composites}

The TEM morphologies of $\mathrm{TiO}_{2}$ Degussa and the synthesised $\mathrm{C}-\mathrm{N}-\mathrm{TiO}_{2}$ nano catalysts earlier presented in Figure $6 a, d, g, j$ were further used to determine the particle size distribution of the catalysts shown in Figure 7c-f using ImageJ Java-based software (developed by Wayne Rasband (retired from the National Institutes of Health and the Laboratory for Optical and Computational Instrumentation (LOCI, University of Wisconsin, Madison, WI, USA).

The TEM size distribution normalised results of the Degussa catalyst presented in Figure 7c show that the particle size distribution of $\mathrm{TiO}_{2}$ of Degussa P25 varied between 5 and $40 \mathrm{~nm}$ and the most abundant $\mathrm{TiO}_{2}$ particle sizes were between 10 and $25 \mathrm{~nm}$ which is in conformity with XRD results.

All synthesised $\mathrm{C}-\mathrm{N}-\mathrm{TiO}_{2}$ specimens were in the nano scale and had smaller crystallite sizes than $\mathrm{TiO}_{2}$ Degussa. As shown in Figure $7 \mathrm{~d}-\mathrm{f}$, among the nano catalysts synthesised in this study, the granular $S_{1}$ had the smallest particle size range of 5 to $6 \mathrm{~nm}$. Apart from being in nanotube shapes, and agglomerated forms, compared to $S_{2}$ and $S_{3}$ obtained after longer pyrolysis time (as shown by SEM analysis), their most abundant particle size ranged consistently in the 6-8 $\mathrm{nm}$ interval. These results confirmed that the size of $\mathrm{C}-\mathrm{N}-\mathrm{TiO}_{2}$ doped nano catalysts increased slightly with an increase in the pyrolysis time.

\subsection{Effect of Pyrolysis Holding Time of $\mathrm{C}-\mathrm{N}-\mathrm{TiO} \mathrm{O}_{2}$ Nano Catalysts on Photocatalytic Decolouration of Orange II Dye}

The photo catalytic activity of Degussa $\mathrm{TiO}_{2}\left(\mathrm{~S}_{0}\right)$ and the synthesised $\mathrm{C}-\mathrm{N}-\mathrm{TiO}_{2}$ nano catalysts was investigated upon the decolouration of O.II sodium salt dye under solar and UV light at the applied conditions and the results are presented in Figure 8. 

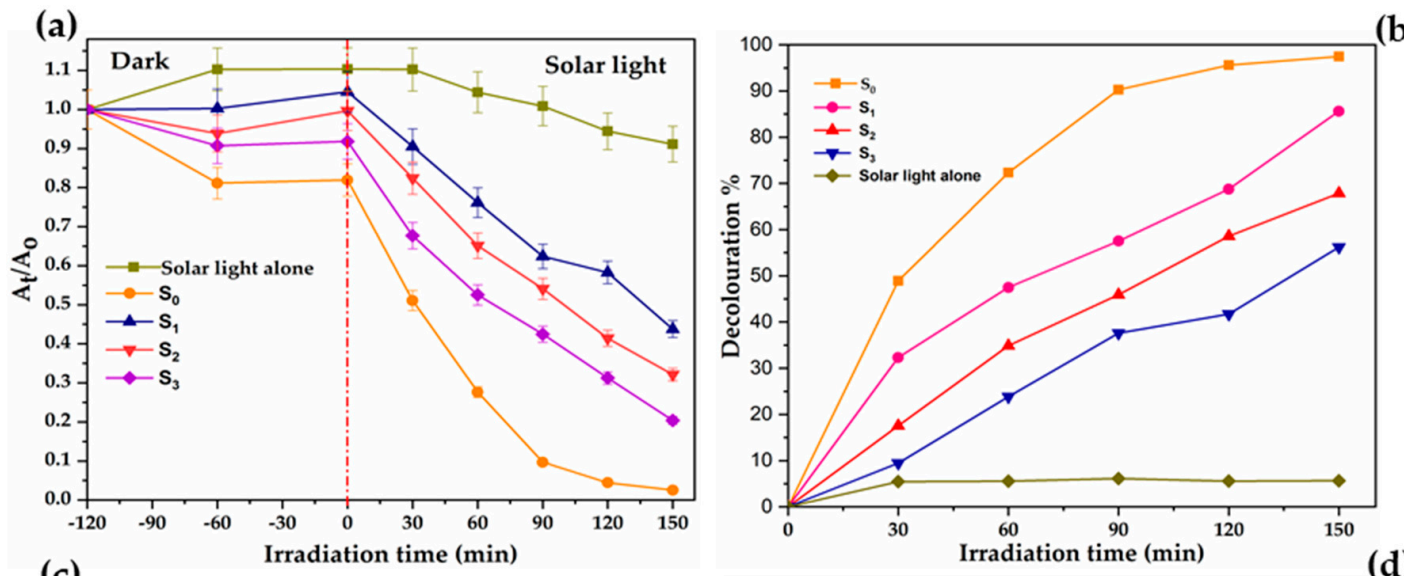

(c)

Irradiation time (min)
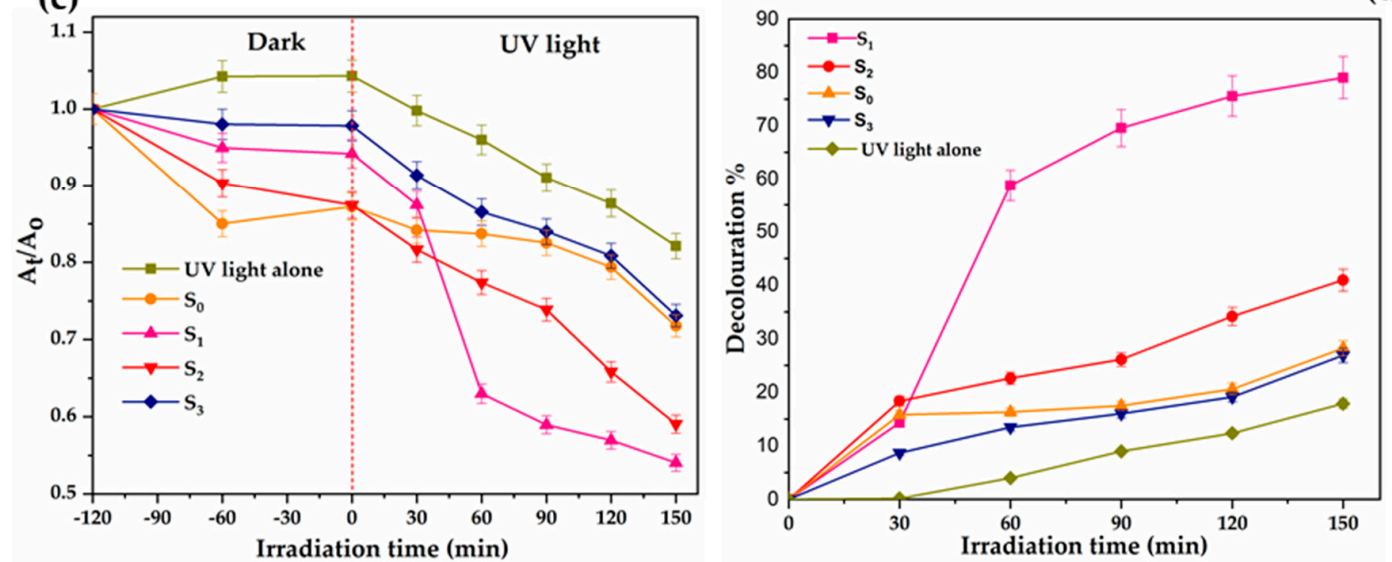

(b)

Figure 8. Photocatalytic decolouration of orange $\mathrm{II}$ by $\mathrm{TiO}_{2}$ Degussa and $\mathrm{C}-\mathrm{N}-\mathrm{TiO}_{2}$ Nano composites pyrolysed at $350{ }^{\circ} \mathrm{C}$ under $\mathrm{N}_{2}$ gas using $50{ }^{\circ} \mathrm{C} / \mathrm{min}$ ramping rate for different holding times $\left(\mathrm{S}_{0}=\right.$ with Degussa $\mathrm{TiO}_{2} ; \mathrm{S}_{1}=\mathrm{C}-\mathrm{N}-\mathrm{TiO}_{2} 105 \mathrm{~min} ; \mathrm{S}_{2}=\mathrm{C}-\mathrm{N}-\mathrm{TiO}_{2} 120 \mathrm{~min}$ and $\mathrm{S}_{3}=\mathrm{C}-\mathrm{N}-\mathrm{TiO}_{2} 135 \mathrm{~min}$ ). $(\mathbf{a}, \mathbf{b})$ kinetics decay and decolouration efficiency of O.II dye in the dark and in solar light correspondingly. (c) and (d) kinetics decay and decolouration efficiency of O.II dye in the dark and in UV light, respectively. Experimental conditions O.II concentration $5 \mathrm{mg} / \mathrm{L}$, volume $500 \mathrm{~mL}, \mathrm{pH}$ 2.5, catalyst dosage $0.08 \mathrm{~g}$ and irradiation time of $150 \mathrm{~min}$. The error bar was extracted from the standard error resulting from two photo catalytic measurements performed with each catalyst $(n=2)$.

The duplicated photo catalysis results presented in Figure 8 show that all $\mathrm{C}-\mathrm{N}-\mathrm{TiO}_{2}$ nano catalysts were photo catalytically active under solar and UV light and the best photocatalytic decolouration of O.II was achieved with $S_{1}$ in both solar and UV light followed by $S_{2}$ and $S_{3}$. The pure $\mathrm{TiO}_{2}$ Degussa showed higher removal rate under solar light compared to $\mathrm{C}-\mathrm{N}-\mathrm{TiO}_{2}$ nano composites due to titanium carbides entities that are assumed to have formed. Since both solar and UV light were used, the improvement of catalysts performance in UV light could be ascribed to the decrease of charge recombination rate (detailed in discussion section). The carbon residues that glued crystals together did not negatively affect $S_{1}$ catalyst activity by much compared to the Degussa $\left(S_{1}\right)$.

In Figure 8a, the photo catalytic results under solar light show that after $150 \mathrm{~min}$ of irradiation, the $\mathrm{C}-\mathrm{N}-\mathrm{TiO}_{2} 105 \mathrm{~min}$ achieved enhanced activity of $85 \%$ compared to $67.9 \%$ or $56 \%$ decolouration rates that were reached with $120 \mathrm{~min}$ and $135 \mathrm{~min} \mathrm{C}-\mathrm{N}-\mathrm{TiO}_{2}$ nano catalysts, correspondingly. This is in accordance with the band gap values earlier recorded in Table 4 which showed that higher dye removal is achieved with catalysts with low band gap and hence compliments the highlights/findings of Jinghong Li and Jin Z. Zhang [50]. This further demonstrated that alteration of calcination holding time results in band gap tailoring which, in turn, affects photo catalytic activity of the nano materials.

On the other hand, the highest photo catalytic decolouration of O.II $97 \%$ in Figure $8 \mathrm{~b}$ achieved with $\mathrm{S}_{0}$ after 150 min of illumination under solar light may be due to the inhibition of $\mathrm{C}-\mathrm{N}-\mathrm{TiO}_{2}$ active 
sites by Ti-C as revealed by XPS. This consequently may have decelerated the activity of the $\mathrm{C}-\mathrm{N}-\mathrm{TiO}_{2}$ catalysts upon increased pyrolysis holding time compared to $\mathrm{TiO}_{2}$ Degussa.

Figure $8 \mathrm{~b}$ shows that the sol-gel synthesised $\mathrm{C}-\mathrm{N}-\mathrm{TiO}_{2}$ nano composites were also active under UV light, with $\mathrm{S}_{1}$ showing an improved activity of $79 \%$ followed by $41 \%$ or $27 \%$ achieved after $150 \mathrm{~min}$ of UV exposure with $S_{2}$ and $S_{3}$, respectively. This was attributed to a retarded electron recombination rate that resulted from the microstates created via incorporation of $\mathrm{C}$ and $\mathrm{N}$ in $\mathrm{TiO}_{2}$ bulk [51]. However, the overall removal rates under UV light were less than those achieved with solar light, probably because the UV lamp (UV-C) used in this study had low power $(18 \mathrm{~W})$ and, hence, reduced intensity.

On the other hand, lower removal percentages of O.II dye achieved with high band gap catalysts could be assigned to poor promotion of excited electrons from the valence band (VB) to the conductive band (CB) and a rapid electron-hole pair recombination rate of the semi-conductor which, in return, retarded the oxidation and reduction reactions occurring on VB and CB energy levels [52]. Indeed, the oxidation of water molecules by the empty holes on the $\mathrm{VB}$ and the reduction of oxygen molecules by highly energised electron on the $\mathrm{CB}$ thus contributed to the production of non-selective hydroxyl radicals $(\mathrm{OH} \cdot)$ that unselectively destroyed the pollutant [15].

Thus, higher band gaps of 3.2, 3.17 and 3.10 limited the production of $\mathrm{OH} \cdot$ and co-produced oxidants under UV light; and thus, low degradation percentages of O.II dye. The correlation of $\mathrm{C}-\mathrm{N}-\mathrm{TiO}_{2}$ activity and other properties previously discussed shows that the granular $\mathrm{C}-\mathrm{N}-\mathrm{TiO}_{2}$ nano composites with particle size of $5.5 \mathrm{~nm}$ and a band gap of $2.6 \mathrm{eV}$ achieved $79 \%$ removal of O.II dye in their mainly anatase phase and is in conformity with Palanivelu and Sun Im [16]. While lower percentage removals of O.II were reached with $\mathrm{C}-\mathrm{N}-\mathrm{TiO}_{2}$ with higher particle sizes 6.3 and $6.4 \mathrm{~nm}$ and band gap (3.10 and $3.17 \mathrm{eV})$.

Consequently, the amount of carbon residue, coupled with the crystal structure, the shape, and the size of nanomaterial have an impact on their photocatalytic activity mainly through band-gap engineering and reducing electron-hole pair recombination rate [53-56].

\section{Discussion}

Semiconductors such as $\mathrm{TiO}_{2}$ are characterised by a valence band (VB) and a conductive band (CB). The VB is governed by positively charged holes while the $\mathrm{CB}$ is populated by negative charge carriers (electrons). The introduction of impurities such as $\mathrm{C}$ and $\mathrm{N}$ into the Ti lattice led to the formation of new sub energy levels mostly in the VB lattice that consequently reduced the band gap of the newly prepared $\mathrm{C}-\mathrm{N}-\mathrm{TiO}_{2}$ nano catalyst according to the intrinsic and extrinsic Fermi-Dirac distribution principal in p-type semiconductors reported by Shriver and Atkins, [57].

Initially after pyrolysis of $\mathrm{C}-\mathrm{N}-\mathrm{TiO}_{2}$ sol-gel for $105 \mathrm{~min}\left(\mathrm{~S}_{1}\right)$ at the applied conditions, the prepared $\mathrm{C}-\mathrm{N}-\mathrm{TiO}_{2}$ had a band gap of $2.6 \mathrm{eV}$. The thermally excited electrons within $\mathrm{VB}$ of the $\mathrm{S}_{1}$ nano catalyst created holes $\left(\mathrm{h}^{+}\right)$in the latter while the remaining electrons were mobile and stored in the acceptor gap. The trapping of thermally excited electrons of VB in the acceptor gap led not only to the upward enlargement/stretching of the $\mathrm{C}-\mathrm{N}-\mathrm{TiO}_{2} \mathrm{VB}$, but prevented the relaxation of the free electrons to their empty holes within the VB. This, therefore, resulted in the shrinking of the $\mathrm{C}-\mathrm{N}-\mathrm{TiO}_{2}$ band gap to $2.67 \mathrm{eV}$ corresponding to a wavelength of $462 \mathrm{~nm}$ characteristic of the visible region that was lower than the $3.2 \mathrm{eV}$ band gap of commercial $\mathrm{TiO}_{2}$ Degussa reported by Carp et al. [45] and Gilmour and Ray [47].

On the other hand, the increase of pyrolysis holding time to $120 \mathrm{~min}$ or $135 \mathrm{~min}$ accelerated the evaporation of $\mathrm{C}$ and $\mathrm{N}$ which consequently resulted in the relaxation of trapped electrons and hence to the decrease of the acceptor gap and the reduction of $\mathrm{C}-\mathrm{N}-\mathrm{TiO}_{2} \mathrm{VB}$ that subsequently caused a slight increase of the $\mathrm{C}-\mathrm{N}-\mathrm{TiO}_{2}$ band gap to 3.1 and $3.17 \mathrm{eV}$, respectively to $393 \mathrm{~nm}$ and $333 \mathrm{~nm}$ characteristics of the UV range (Schematically shown in Figure 9). 

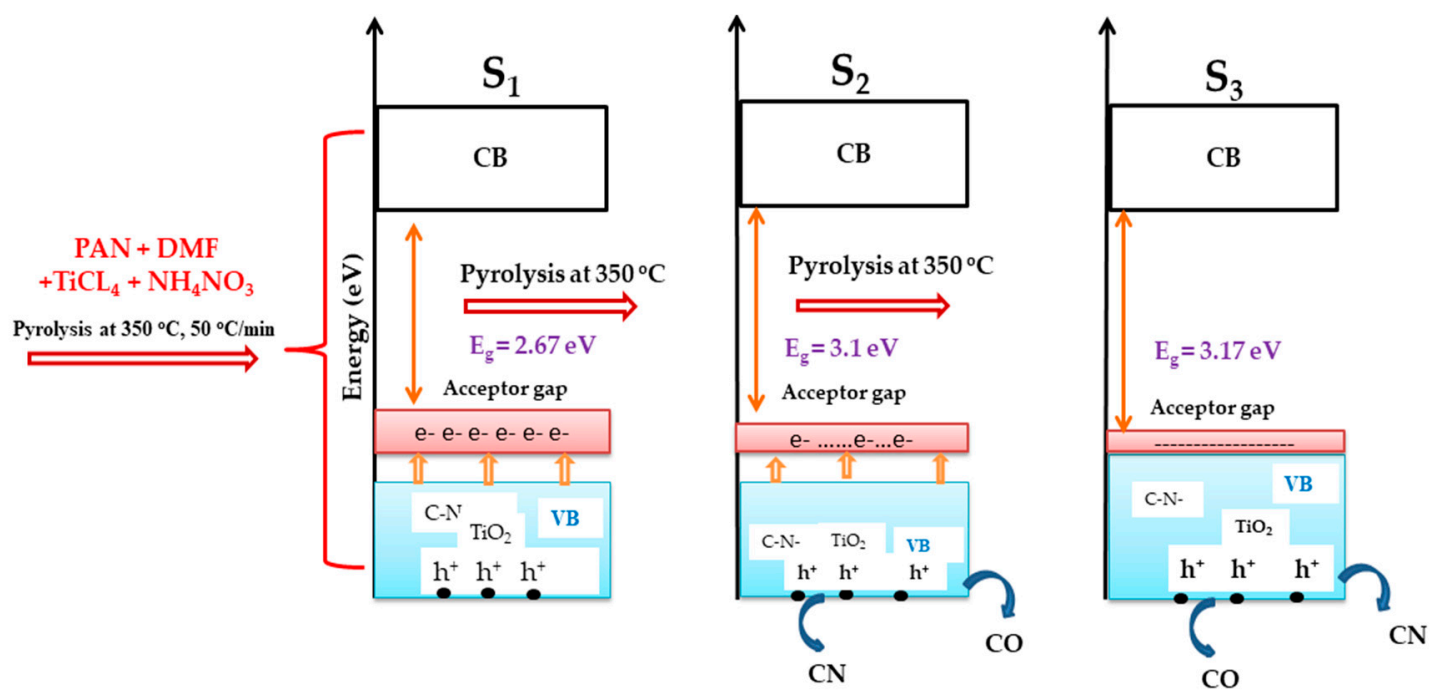

Figure 9. Schematic of changes occurring during pyrolysis of $\mathrm{C}-\mathrm{N}-\mathrm{TiO}_{2}$ at $350{ }^{\circ} \mathrm{C}$ for different holding times 105, 120 and $135 \mathrm{~min}\left(\mathrm{~S}_{1}=\mathrm{C}-\mathrm{N}-\mathrm{TiO}_{2} 105 \mathrm{~min} ; \mathrm{S}_{2}=\mathrm{C}-\mathrm{N}-\mathrm{TiO}_{2} 120 \mathrm{~min}\right.$ and $\mathrm{S}_{3}=\mathrm{C}-\mathrm{N}-\mathrm{TiO}_{2}$ $135 \mathrm{~min})$.

These findings are in accordance with Shriver and Atkins, [57] and Mu et al. [58] who claimed that decreasing concentration of impurities may result in band gap increase with high energy that may reduce the photocatalytic activity of the nano catalyst. Their statement is in conformity with the TEM-EDS percentage abundance of $C$ and $\mathrm{N}$ disclosed in Table 3 that decreased from 72 to $40 \%$ and from 7.1 to $3.63 \%$, respectively when the pyrolysis holding time was increased from 105 to 135 min, correspondingly.

This was further supported by the functional groups such as $\mathrm{C}=\mathrm{O}, \mathrm{N}=\mathrm{O}$, etc. depicted by FIIR in Table 2 and the mass loss\% dictated by TGA in Figure 2. Furthermore, the SAED data in Figure 6 showed that the synthesised $\mathrm{C}-\mathrm{N}-\mathrm{TiO}_{2}$ catalysts have dominant anatase and minimal rutile phases present in the crystal structure that were earlier confirmed by XRD and Raman analysis in Figure 1. The decrease in carbon and nitrogen content was probably due to the diffusion of $\mathrm{C}$ and $\mathrm{N}$ toward the surface of the nanocomposites which later formed gases or volatile degradation by-products as PAN decomposed during the pyrolysis process according to Darányi Mária et al. [33]. A few authors [59,60] suggested that the relaxation and evaporation of non-metals such as $\mathrm{C}$ and $\mathrm{N}$ in $\mathrm{TiO}_{2}$ lattice similarly observed in the current study could be prevented or minimized by extended co-doping of the $\mathrm{C}-\mathrm{N}-\mathrm{TiO}_{2}$ with transition metals, such as nobidium $(\mathrm{Nb})$ and Thallium $(\mathrm{Ta})$, to achieve stable co-dope $\mathrm{TiO}_{2}$ based catalysts with reduced energy gap, improved optical absorption and enhanced carrier mobility.

Thus, altering the pyrolysis holding time allows control of the amount of $\mathrm{C}$ and $\mathrm{N}$ around and in the $\mathrm{TiO}_{2}$ lattice framework. This resulted not only in band gap tailoring but also may have retarded the relaxation of the free electrons stored in the acceptor gap to their empty holes created within the $\mathrm{VB}$ of $\mathrm{C}-\mathrm{N}-\mathrm{TiO}_{2}$ lattice [31,32]. It is worthwhile to mention that these electron motions occurred in microstates within the valence band of the $\mathrm{C}-\mathrm{N}-\mathrm{TiO}_{2}$ catalysts when pyrolysis holding time was being tuned before photo catalytic applications and hence justifies the changes in catalysts band gap observed in Figures $7 \mathrm{~b}$ and 9. In order to test (the exclusion of) this hypothesis further, photocatalytic experiments were conducted under solar and UV light, which showed the effect of charge recombination rates between VB and CB of the catalysts (Figure 10) rather than band gap tailoring. 


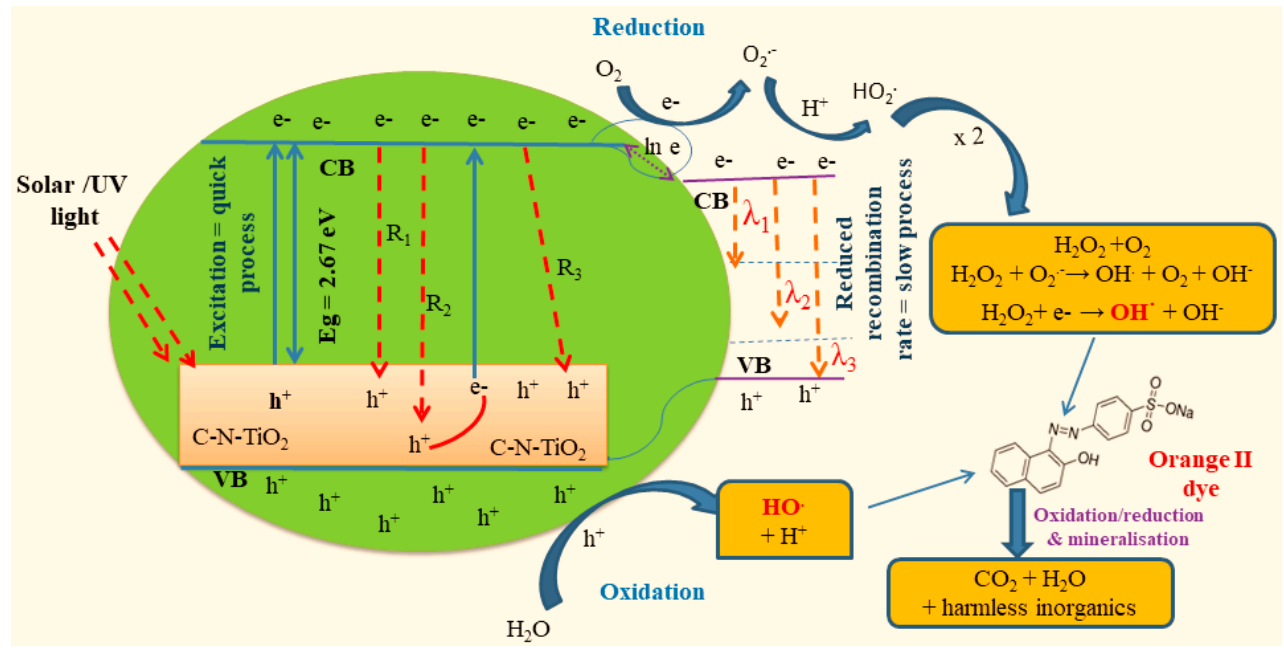

Figure 10. Schematic of photo catalytic and recombination mechanisms for the decolouration of O.II $\left(R_{1}, R_{2}\right.$ and $R_{3}=$ recombination mechanisms between conduction band $(C B)$ and valence band $(V B)$, $\left(\lambda_{1}, \lambda_{2}\right.$ and $\lambda_{3}=$ recombination mechanisms between $C B$ and $p$ empty orbitals of $C$ and $N$ dopants).

Furthermore, despites the various motivations highlighted above, it could still be stated that the reason behind the reduction of the band gap is unclear; $\mathrm{C}$ and $\mathrm{N}$ may have entered the crystal structure and acted as dopants, i.e., replacing partially $\mathrm{O}^{2-}$ or $\mathrm{Ti}^{4+}$. However, this would imply one or more mechanisms for charge balancing, in order to maintain the overall neutral charge of the compound. The charge is not altered if $\mathrm{C}^{4+}$ partially replaces $\mathrm{Ti}^{4+}$ but the nature of the $\mathrm{N}$ substitution is less straightforward. If $\mathrm{N}$ enters the structure as anion, $\mathrm{N}^{3-}$, then it would partially replace the $\mathrm{O}^{2-}$ anion causing a charge imbalance. Potentially, the charge compensation mechanism to re-balance this excess of negative charge could be the formation of anion vacancies. It would be these anion vacancies that form the acceptor additional bands to which the shrinking of the band gap could be attributed, due to the presence of $\mathrm{Ti}^{3+}$ for charge balancing. This hypothesis was verified by XPS analysis that confirmed the presence of $\mathrm{Ti}^{3+}$ deriving mostly from the reduction of $\mathrm{Ti}^{4+}$. Alternatively, the $\mathrm{C}$ and $\mathrm{N}$ species only form functional groups on the surface of the nanoparticles as a consequence of $\mathrm{C}$ and $\mathrm{N}$ diffusion during pyrolysis of PAN, perhaps replacing oxide anions to form bonding systems, such as Ti-C and $\mathrm{Ti}-\mathrm{N}$, and causing, again, anion vacancies, which influenced the band gap. This scenario is more in agreement with the FTIR and XPS results. Furthermore, the relatively low temperature at which the pyrolysis process was carried out is not conducive to cation or even anion substitution in a stable compound such as $\mathrm{TiO}_{2}$.

The fact that $\mathrm{C}-\mathrm{N}-\mathrm{TiO}_{2}$ nano composites were active under both solar and UV light at a reduced band gap suggested that the electron-hole pair's recombination rate was slowed down as described in Figure 10. This might have contributed to a significant storage of electrons in the conduction band (CB) and creation of more vacant holes in the valence band (VB) and consequently increased the concentration of $\mathrm{OH} \cdot$ and related species that decolourised the polluted water [61]. Therefore, the retarded electron-hole recombination process was the driving force behind the improved O.II degradation.

Indeed, during the photocatalytic irradiation process, the electrons stored in the $\mathrm{CB}$, were largely involved in reduction of $\mathrm{O}_{2}$ to superoxide anions producing free radicals $\mathrm{OH}$. and related oxidants that effectively attacked O.II pollutant [62]. On the other hand, the oxidation of $\mathrm{H}_{2} \mathrm{O} / \mathrm{OH}^{-}$acid-base conjugate system by the positive empty holes on the VB contributed to boosting the amount of $\mathrm{OH} \cdot$ in the contaminated water and quickly induced the fading of O.II dye [54,55].

Apart from excitation intensities, electrical potential and electrolyte composition aspects that Haque et al. [63] claimed to affect the electron-hole pairs (e-h) recombination process, the deceleration of electron-hole recombination rate of $\mathrm{C}-\mathrm{N}-\mathrm{TiO}_{2}$ synthesised in this investigation was certainly due to 
transitions such as the Shockley-Read-Hall Model (SRH model) recombination $\left(\mathrm{R}_{2}\right)$ and the Auger recombination $\left(R_{3}\right)$. These mechanisms might have retarded the principal band to band recombination process $\left(R_{1}\right)$ that consequently led to the proliferation of charge carriers (electrons and positive empty holes) in the $\mathrm{CB}$ and $\mathrm{VB}$, respectively [52]. These consequently empowered the generation of a significant number of free radicals in the polluted water and hence enhanced the decolouration of O.II dye.

Moreover, the slowing of $(\mathrm{e}-\mathrm{h})$ recombination rate could also be ascribed to the intrinsic electron transitions $\left(\lambda_{1}\right.$ and $\left.\lambda_{2}\right)$ occurring when accumulated electrons preferentially migrated from the $C B$ to the nearest vacant $p$ orbitals of $\mathrm{C}$ and $\mathrm{N}$ dopants fused in $\mathrm{TiO}_{2}$ matrix [64] as shown in Figure 10. In this regard, $\lambda_{1}$ and $\lambda_{2}$ decelerated the completion of band to band $\left(\lambda_{3}\right)$ transition in the VB, resulting in the generation of more charge carriers and hence increased the concentration of free active species from the oxidation and reduction processes occurring in both VB and CB bands, respectively. This consequently advanced the oxidative removal of O.II dye.

Thus, the high photo catalytic removal of O.II achieved with $\mathrm{S}_{1}$ under solar and UV-light, demonstrated that $\mathrm{C}-\mathrm{N}-\mathrm{TiO}_{2}$ nano catalysts had a high electron storing capacity and a reduced/low recombination rate. The outcomes of this work showed that combining $\mathrm{TiO}_{2}$ with high amounts of non-metal $\mathrm{C}$ and $\mathrm{N}$ residues through pyrolysis of $\mathrm{PAN}$ and $\mathrm{NH}_{4} \mathrm{NO}_{3}$ resulted in a highly active catalyst with a reduced band gap $2.67 \mathrm{eV}$ and a low electron-hole pair recombination rate that can be used under solar and artificial (UV) light [21,22].

In this process, while PAN as the source of carbon and nitrogen was reported to decompose to various monomers and other species such as $\mathrm{HCN}, \mathrm{NH}_{3}, \mathrm{H}_{2} \mathrm{O}$ and $\mathrm{CO}_{2}$ [29]; $\mathrm{NH}_{4} \mathrm{NO}_{3}$, on the other hand, likely decomposed to nitrous oxides $[30,65]$ that were evident from the FTIR results.

The systematic alteration of pyrolysis holding time allowed control of the amount of $\mathrm{C}$ and $\mathrm{N}$ upon and around $\mathrm{TiO}_{2}$ and resulted in the fabrication of carbon- and nitrogen-rich catalysts with a tuneable band gap and low electron-hole pair recombination rate and tuneable band gap that can be used under both solar and UV light. So, the exposure of the as-prepared $\mathrm{C}-\mathrm{N}-\mathrm{TiO}_{2}$ nano catalysts under solar light boosted the decolouration of the textile dye much more rapidly than in UV light as shown in Figure 8. In this regard, we believe that various aspects including solar and UV light intensity/power need to be considered in photo catalysis experiments. Another aspect impeding the activity of $\mathrm{C}-\mathrm{N}-\mathrm{TiO}_{2}$ nano composites was the appearance of titanium carbides (Ti-C) on the surface of the catalysts as a result of $C$ diffusion from the bulk to the surface of the catalyst during pyrolysis of PAN when increasing calcination time from 105, 120 to $135 \mathrm{~min}$.

Moreover, the treatment time of $150 \mathrm{~min}$ could have been short/limited to reach completion of catalytic activity. This could also be observed from Figure $8 \mathrm{a}-\mathrm{c}$ in which extrapolation of O.II degradation graphs to about two more hours could reach its complete decolouration. This could be considered as future task of this study.

Since we proved that the sol-gel/pyrolysis synthesised nano composites were active under both solar and UV light, this hence demonstrates its application in various areas of environmental remediation such as water and wastewater purification and solar cell technologies.

Furthermore, for any advanced oxidation system producing UV-light, such as the dielectric barrier discharge system $[20,66-70]$, the synthesised $\mathrm{C}-\mathrm{N}-\mathrm{TiO}_{2}$ is best used to improve the efficiency of the generated UV light towards the decolouration of organic dye contaminants. The sol-gel synthesis route proposed in this work can be used as a rapid and effective technique for the fabrication of $\mathrm{C}-\mathrm{N}-\mathrm{TiO}_{2}$ nano-catalyst with controlled band gap and low recombination rate of electron-hole pairs for photocatalytic applications in both UV and visible light.

\section{Materials and Methods}

A magnetic stirrer Hei-Mix S-UK $230 \mathrm{~V} / 50 \mathrm{~Hz}$ with UK plug (purchased from Laboratory Equipment South Africa, Athlone, Cape Town, 7760, South Africa) was used during sol-gel mixing, ceramic crucibles, an $805 \mathrm{~cm}$ furnace tube made in quartz connected to a nitrogen gas inlet set at 
$100 \mathrm{~mL} / \mathrm{min}$ were used to pyrolyse in $\mathrm{N}_{2}$ the $\mathrm{C}-\mathrm{N}-\mathrm{TiO}_{2}$-doped photo catalyst. The illumination sources were stimulated solar light (AM 1.5 radiation, $100 \mathrm{~mW} / \mathrm{cm}^{2}$ ) obtained from a solar simulator (Sciencetech SS1.6 kW, London, ON, Canada) for photo degradation. A LUX meter (ISO-TECH ISM 410) was used to determine the location that achieved the required light intensity, and a UV lamp (Mega-Ray 160 W/240 V MR160 SPL11/14 from Kimix, Airport Industria, Cape Town, South Africa) and the photo catalytic setup shown in Figure 1 were used to perform the photo catalysis experiments elaborated in this study. The chemicals used were polyacrylonitrile (PAN) powder $(99.5 \%$, Good fellow Cambridge Ltd., Cambridge, UK); titanium tetrachloride (MW $189.68 \mathrm{~g} / \mathrm{mol}$, Sigma-Aldrich, Cape Town, South Africa); titanium (IV) oxide (powder), Degussa (99.5\%, Sigma-Aldrich); N,N-dimethyl formamide (DMF) 99\%, Industrial Analytical (Pty), Cape Town South Africa); ammonium nitrate, ACS (95\%, Industrial Analytical (Pty), Cape Town South Africa); sulfuric acid (98\%, Kimix Airport Industria, Cape Town, South Africa ); sodium hydroxide flakes CP (97\%, Kimix RSA) and orange II sodium salt (85\%, Sigma-Aldrich, Cape Town, South Africa) were used for the synthesis of carbon-nitrogen co-doped catalysts $\left(\mathrm{C}-\mathrm{N}-\mathrm{TiO}_{2}\right)$ and applied in the photocatalytic degradation of orange II dye under UV illumination.

\subsection{Preparation of $5 \%$ Ammonium Nitrate Solution}

Approximately $5 \mathrm{~g}$ of $95 \%$ granular $\mathrm{NH}_{4} \mathrm{NO}_{3}$ was weighed and dissolved in a $100 \mathrm{~mL}$ volumetric flask and made up to the mark with distilled water. The prepared $5 \% \mathrm{NH}_{4} \mathrm{NO}_{3}$ was stored for further experiments.

\subsection{Preparation of $\mathrm{C}-\mathrm{N}-\mathrm{TiO}_{2}$ Sol-Gel and Pyrolysis Protocol}

Eight grams of PAN powder were weighed and mixed with $100 \mathrm{~mL}$ of $99 \%$ DMF in a $200 \mathrm{~mL}$ capped borosilicate glass bottle and stirred for $24 \mathrm{~h}$ at room temperature to dissolve it. Approximately $3 \mathrm{~mL}$ of $98 \%$ concentrated $\mathrm{TiCl}_{4}$ was added dropwise into the prepared $8 \%$ PAN/DMF mixture and stirred in a fume hood until the white $\mathrm{HCl}$ fumes disappeared from the resultant sol-gel. Moreover, $3 \mathrm{~mL}$ of $5 \% \mathrm{NH}_{4} \mathrm{NO}_{3}$ was added dropwise into the $\mathrm{C}-\mathrm{TiO}_{2}$ sol-gel obtained and stirred for 15 to $30 \mathrm{~min}$ until the colour of the mixture slightly changed from brownish to yellow-brownish. Ceramic sample holders cleaned with acetone and ethanol, followed by distilled water, were dried in an oven at $25^{\circ} \mathrm{C}$ for $15 \mathrm{~min}$ and cooled. Thereafter, 5 to $10 \mathrm{~mL}$ of the prepared $\mathrm{C}-\mathrm{N}-\mathrm{TiO}_{2}$ gel was introduced into the washed sample holders and heated in a furnace using a ramping rate of $50^{\circ} \mathrm{C} / \mathrm{min}$ under a nitrogen gas flow of $20 \mathrm{~mL} / \mathrm{min}$ and annealed for different pyrolysis holding times of $105 \mathrm{~min}, 120 \mathrm{~min}$ or $135 \mathrm{~min}$ at $350^{\circ} \mathrm{C}$, respectively, according to methods developed by Totito [71]. The prepared catalysts were ground in a mortar and pestle until a fine powder was obtained which was used for characterisation and photo catalytic applications.

In the following the samples were noted as: $\mathrm{S}_{0}-\mathrm{TiO}_{2}$ Degussa; $\mathrm{S}_{1}-\mathrm{C}-\mathrm{N}-\mathrm{TiO}_{2} 105 \mathrm{~min}$; $\mathrm{S}_{2}-\mathrm{C}-\mathrm{N}-\mathrm{TiO}_{2} 120 \mathrm{~min}$ and $\mathrm{S}_{3}-\mathrm{C}-\mathrm{N}-\mathrm{TiO}_{2} 135 \mathrm{~min}$.

\subsection{Characterisation of Powdered $\mathrm{C}-\mathrm{N}-\mathrm{TiO}_{2}$ Photo Catalyst}

Various techniques were used for the characterisation of powder $\mathrm{C}-\mathrm{N}-\mathrm{TiO}_{2}$ nano catalysts. The phase composition of the samples $\left(\mathrm{C}-\mathrm{N}-\mathrm{TiO}_{2}\right.$ powder) was investigated by $\mathrm{X}$-ray diffraction (XRD) using a Smart Lab diffractometer (Rigaku), with a CuK $\alpha$ radiation $(\lambda=0.15405 \mathrm{~nm})$. The XRD patterns were obtained in a $2 \theta$ range of $20^{\circ}$ to $100^{\circ}$, at a step size of $0.02^{\circ}$.

A scanning electron microscope (SEM) (FEI Nova NanoSEM 230 SEM manufactured by the FEI factory in Poland that was recently tasken over by Thermo Fisher Waltham, Waltham, MA, USA) coupled with an energy-dispersive X-ray spectrometer (EDS) was used for the surface morphology and elemental composition investigation. Images of the surface morphology for each specimen were recorded at both $30 \times$ and 100 $\times$ magnification. The EDS was obtained using an Oxford instruments (X-Max $20 \mathrm{~mm}^{2}$ detector, using Oxford INCA software manufactured by Oxford Instruments, Oxford, 
UK). The identification of carbon, nitrogen and titanium distribution in the $\mathrm{C}-\mathrm{N}-\mathrm{TiO}_{2}$ samples and mapping elemental images was acquired in different areas of the sample surface.

The thermal gravimetric (TGA) was used to evaluate the mass loss percentage of the synthesised co-doped $\mathrm{C}-\mathrm{N}-\mathrm{TiO}_{2}$ catalysts; hence showing the effect of pyrolysis and degradation of the carbon source (PAN) using a PerkinElmer Thermo gravimetric analyser TGA 4000 (purchased from PerkinElmer, Inc. 940 Winter Street Waltham, MA 02451, USA).

The analysis was performed in the temperature range of 0 to $850{ }^{\circ} \mathrm{C}$ in $\mathrm{N}_{2}$ gas. After $2 \mathrm{~h}$, the results obtained were collected from the PC and plotted using excel software. The graphs of weight $(\mathrm{mg}) /$ weight percentage versus temperature $\left({ }^{\circ} \mathrm{C}\right)$ were obtained.

The various vibration bands of different functional groups were identified by Fourier transform infrared spectroscopy (FTIR) using a Perkin Elmer spectrum 100 FTIR spectrometer set in the range of $4000-380 \mathrm{~cm}^{-1}$. After the desired background was measured, the baseline was corrected and the spectra were smoothened.

Electron energy-loss spectroscopy (EELS) and X-ray photoluminescence spectroscopy (XPS) analysis were carried out to verify the chemical states/bonding and surface composition of $\mathrm{C}-\mathrm{N}-\mathrm{TiO}_{2}$ nano materials after pyrolysis.

X-ray photoelectron spectroscopy (XPS) spectra were carried out using multiprobe photoelectron spectroscopy (Omicron Nanotechnology, Taunusstein, Germany). A monochromatic Al K $\alpha$ radiation $(\mathrm{h} v=1486.6 \mathrm{eV}$ ) of source voltage $15 \mathrm{kV}$ and an emission current of $20 \mathrm{~mA}$ was employed for measurement. All scans were done at a base pressure of $\sim 2 \times 10^{-8} \mathrm{~Pa}$. The composition of the sample was extracted from the wide scan (survey scan), while the individual element peaks (high resolution scan) were recorded at a constant analyser transmission energy of $20 \mathrm{eV}$. As charging effects are unavoidable in an XPS study of non-conducting samples, charge compensation was performed by flooding of electron from neutralizer electron gun. The obtained XPS spectra were deconvoluted to individual components using Gaussian Lorentzian function in Casa XPS software (Casa Software Ltd., Terrace Teignmouth, TQ148NE, UK). The binding energies were calibrated with respect to adventitious hydrocarbon $\mathrm{C} 1 \mathrm{~s}$ feature at $284.6 \mathrm{eV}$.

In these processes, Degussa $\mathrm{TiO}_{2}$ powder was used as control and for comparison purposes.

The band gap of the catalysts was calculated using the Equations (2)-(5) from Kubelka-Munk theory.

$$
\begin{gathered}
A=\log \left(\frac{1}{R}\right) \\
K=\frac{(1-R)^{2}}{2 R} \\
E(e V)=\frac{h v}{\lambda} \\
v=\frac{c}{\lambda}
\end{gathered}
$$

where $A$ is the absorbance of the sample converted to scattering coefficient (diffusion reflectance) $(R)$; $K$ is the adsorption coefficient, $h=6.626 \times 10^{-34} \mathrm{~m}^{3} \cdot \mathrm{kg} / \mathrm{s}$ Planck's constant, $c=2.997 \times 10^{8} \mathrm{~m} / \mathrm{s}$ the speed of light and $\lambda(\mathrm{nm})$ the wavelength at the corresponding sample absorbance.

The TEM micrographs were imaged using a Tecnai $G$ squared 20 (Tecnai $G^{2} 20$ ) field-emission TEM operated at $200 \mathrm{kV}$ in bright-field mode, whereas all EDS data analysed during TEM studies were collected with a EDAX liquid nitrogen cooled lithium doped silicon detector. All EELS spectra were recorded with a Gatan GIF-2001 energy filter attached to the Tecnai $G^{2} 20$ TEM; each spectrum was collected over 20 to 50 frames, each timed at $5 \mathrm{~ms}$ to limit electron beam radiation damage. In addition, to remove plural electron scattering and contribution from low energy plasmons, each spectrum was deconvoluted with the standard Log-Fourier iterative process (build into the Gatan Digital Micrograph Suite) and background subtracted using a power law function. Selected area electron diffraction 
(SAED) patterns of small clusters of nano-catalysts were collected using a $1 \mu \mathrm{m}$ diameter selected area aperture in parallel beam mode.

\subsection{Photo Catalytic Irradiation of Orange II Dye}

The activity of the photo catalysts pyrolysed at $350{ }^{\circ} \mathrm{C}$ for $105 \mathrm{~min}\left(\mathrm{~S}_{1}\right), 120 \mathrm{~min}\left(\mathrm{~S}_{2}\right)$ or $135 \mathrm{~min}$ $\left(\mathrm{S}_{3}\right)$ was evaluated and compared with Degussa P25 using the photo catalysis procedure described in Figure 11.

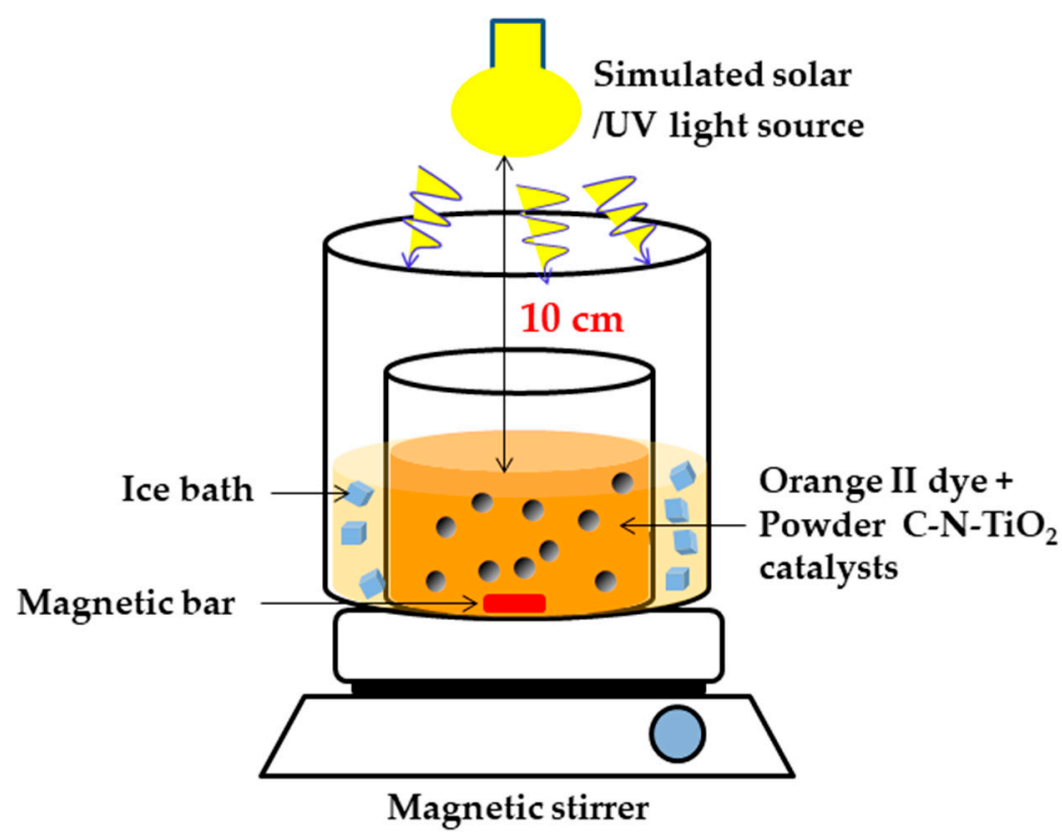

Figure 11. Photo catalysis set up for the degradation of orange II dye.

Approximately, $500 \mathrm{~mL}$ of $5 \mathrm{mg} / \mathrm{L}$ orange II solution at $\mathrm{pH} 2.5$ was introduced in a $1000 \mathrm{~mL}$ vessel in which $0.08 \mathrm{~g}$ of ground powder $\mathrm{S}_{1}, \mathrm{~S}_{2}$ and $\mathrm{S}_{3}$ catalysts were added. The $\mathrm{pH}$ of 2.5 was chosen based on previous research outcomes supporting that azo dyes degrade well in acidic medium [72-74].

The vessel was placed in a photocatalytic system around which ice was packed to maintain consistent low temperature. This vessel was positioned on a magnetic stirrer. While stirring at 200 revolutions per minute (rpm), orange II dye solution was irradiated for $150 \mathrm{~min}$ with solar or UV light positioned at $10 \mathrm{~cm}$ above the $400 \mathrm{~mL}$ dye solution in the vessel. The solution was sampled every $30 \mathrm{~min}$, and the samples were analysed using a GBC UV/VIS 920 spectrometer in the range of 200 to $800 \mathrm{~nm}$. The quartz Suprasil cuvettes and deionised water were utilised to define the absorbance of O.II samples recorded at $284 \mathrm{~nm}$.

The unknown concentrations of orange II solution were determined using the linear trend $y=0.069 x$ obtained from standard concentrations of O.II versus absorbance, which was further used to calculate the degradation efficiency $D$ of orange II dye using Equation (6). The synthesised catalyst was used under solar or UV light to validate the efficiency of the photo catalyst under both solar or UV light as in the AOPs reported by Tijani et al. [49].

$$
D(\%)=\left[\frac{A_{o}-A_{t}}{A_{o}}\right] \times 100
$$

where $A_{o}$ represents orange II initial absorbance and $A_{t}$, the absorbance of the dye at time $t$. 


\section{Conclusions}

A C and $\mathrm{N}$ co-doped $\mathrm{TiO}_{2}$ photo catalyst was prepared via sol-gel and pyrolysis method and found to be highly active in visible and UV light. Then the influence of pyrolysis holding times on its physicochemical properties and catalytic performance was investigated in detail. The $\mathrm{C}-\mathrm{N}-\mathrm{TiO}_{2} \mathrm{was}$ pyrolysed using a ramping rate of $50{ }^{\circ} \mathrm{C} / \mathrm{min}$ and held at $350{ }^{\circ} \mathrm{C}$ for different times of 105,120 and $135 \mathrm{~min}$. This study showed for the first time that pyrolysis holding time has an effect on carbon, nitrogen and $\mathrm{TiO}_{2}$ content as well as the band gap, shape and particle size and, thus, upon the photocatalytic activity of the prepared photo catalysts.

Carbon and nitrogen residues were present in substantial quantities upon the $\mathrm{TiO}_{2}$ matrix. When increasing pyrolysis time beyond $105 \mathrm{~min}$, the $\mathrm{C}$ and $\mathrm{N}$ content was reduced through thermal evaporation of gases and their benefit was lost, as seen by the photocatalytic activity which decreased. Changes in C/N content were evidenced by FTIR and EDS results as well as by TGA and XPS. The $\mathrm{C}-\mathrm{N}-\mathrm{TiO}_{2}$ band gap estimated at $2.67 \mathrm{eV}$ after $105 \mathrm{~min}$ pyrolysis increased to 3.10 and $3.17 \mathrm{eV}$ when pyrolysis time increased to 120 or $135 \mathrm{~min}$, respectively.

The synthesised $\mathrm{C}-\mathrm{N}-\mathrm{TiO}_{2}$ nano-photo catalysts pyrolysed for $105 \mathrm{~min}$ showed excellent photocatalytic activity when solar or UV irradiation was applied as a consequence of reduced band gap or electron-hole pair recombination rate, respectively. Hence this fabricated C-N-TiO $\mathrm{Can}_{2}$ be used under solar light or in any system generating UV light to enhance the production of free radicals and hence improve the degradation of organic pollutants.

Author Contributions: E.S.M.M., M.D., O.O.F., A.C.P., A.V., M.B. and L.F.P. planned the research and synthesised/developed the nano catalysts, F.C., M.T.Z.M., H.H.K., M.A. and E.S.M.M. performed the characterisation of the powder $\mathrm{C}-\mathrm{N}-\mathrm{TiO}_{2}$ nano catalysts; E.S.M.M., M.T.Z.M., H.H.K., M.A.-A., S.D. and L.F.P. conducted the Raman, XPS and tested the activity of the catalysts upon decolouration of O.II dye under solar and UV irradiations; E.S.M.M., L.F.P., M.G.F., S.P., A.D.C., A.A., M.D. and M.B. examined the data and provided positive input in data interpretation and supervised the work. E.S.M.M., M.D., O.O.F., A.C.P., A.V., M.B. and L.F.P. wrote the first draft of the manuscript; the work was reviewed and approved by all authors before submission to the journal. All authors have read and agreed to the published version of the manuscript

Funding: The authors are grateful for the financial support from NRF UID104018 and UEFSISCDI-Romania 14BM/14.07.2016 and Oman/RSA Cooperation Programme (project reference no. UID: 111007).

Acknowledgments: The authors also thank all funders, the Water Research Commission SA, and the NRF South Africa. M.D., A.C.P., A.V. and M.B. acknowledge the support of the Romanian Ministry of Research and Innovation through the Core Program, Project no. 18N/2019. A.A., S.P. and A.D. gratefully acknowledge funding from European Union's Horizon 2020 Research Innovation Program under grant agreement GrapheneCore3 and Spearhead Project 5 GRAPES SGA 881603. ADC gratefully acknowledges the financial support from the Ministry of Education and Science of the Russian Federation in the framework of Increase Competitiveness Program of NUST MISIS (No K2-2019-13). Our extended thanks go to Mrs Miranda Walddron at the University of Cape Town for her assistance and guidance in SEM and EDS analysis.

Conflicts of Interest: The authors declare no conflict of interest for publishing this work.

Future Prospects: As future prospects, the catalysts synthesised in this study could be used in DBD plasma systems to make use of the UV light generated and, hence, enhance the detoxification of the targeted pollutants.

\section{References}

1. Kümmerer, K. The presence of pharmaceuticals in the environment due to human use-present knowledge and future challenges. J. Environ. Manag. 2009, 90, 2354-2366. [CrossRef] [PubMed]

2. Esplugas, S.; Bila, D.M.; Krause, L.G.T.; Dezotti, M. Ozonation and advanced oxidation technologies to remove endocrine disrupting chemicals (EDCs) and pharmaceuticals and personal care products (PPCPs) in water effluents. J. Hazard. Mater. 2007, 149, 631-642. [CrossRef] [PubMed]

3. Sirés, I.; Brillas, E.; Sadornil, I.S. Remediation of water pollution caused by pharmaceutical residues based on electrochemical separation and degradation technologies: A review. Environ. Int. 2012, 40, $212-229$. [CrossRef] [PubMed] 
4. Feng, Y.; Song, Q.; Lv, W.; Liu, G. Degradation of ketoprofen by sulfate radical-based advanced oxidation processes: Kinetics, mechanisms, and effects of natural water matrices. Chemosphere 2017, 189, $643-651$. [CrossRef] [PubMed]

5. Huang, W.; Bianco, A.; Brigante, M.; Mailhot, G. UVA-UVB activation of hydrogen peroxide and persulfate for advanced oxidation processes: Efficiency, mechanism and effect of various water constituents. J. Hazard. Mater. 2018, 347, 279-287. [CrossRef] [PubMed]

6. Chen, C.; Feng, H.; Deng, Y. Re-evaluation of sulfate radical based-advanced oxidation processes (SR-AOPs) for treatment of raw municipal landfill leachate. Water Res. 2019, 153, 100-107. [CrossRef] [PubMed]

7. Klavarioti, M.; Mantzavinos, D.; Fatta-Kassinos, D. Removal of residual pharmaceuticals from aqueous systems by advanced oxidation processes. Environ. Int. 2009, 35, 402-417. [CrossRef] [PubMed]

8. Klamerth, N.; Rizzo, L.; Malato, S.; Maldonado, M.I.; Agüera, A.; Fernández-Alba, A.R. Degradation of fifteen emerging contaminants at microg 1(-1) initial concentrations by mild solar photo-Fenton in MWTP effluents. Water Res. 2010, 44, 545-554. [CrossRef]

9. Zhao, F.; Liu, Y.; Hammouda, S.B.; Doshi, B.; Guijarro, N.; Min, X.; Tang C-Jian Sillanpaa, M.; Sivula, K.; Wang, S. MIL-101(Fe)/g-C3N4 for enhanced visible-light-driven photocatalysis toward simultaneous reduction of $\mathrm{Cr}$ (VI) and oxidation of bisphenol A in aqueous media. Appl. Catal. B Environ. 2020, 272, 119033. [CrossRef]

10. Alemany, L.; Bañares, M.A.; Pardo, E.; Jiménez, F.D.P.M.; Blasco, J. Morphological and Structural Characterization of a Titanium Dioxide System. Mater. Charact. 2000, 44, 271-275. [CrossRef]

11. Khan, M.; Bhatti, K.; Qindeel, R.; Alonizan, N.; Althobaiti, H.S. Characterizations of multilayer ZnO thin films deposited by sol-gel spin coating technique. Results Phys. 2017, 7, 651-655. [CrossRef]

12. Cheng, X.; Yu, X.; Xing, Z.; Wan, J. Enhanced Photocatalytic Activity of Nitrogen Doped $\mathrm{TiO}_{2} \mathrm{Anatase}$ Nano-Particle under Simulated Sunlight Irradiation. Energy Procedia 2012, 16, 598-605. [CrossRef]

13. Sambandam, B.; Surenjan, A.; Philip, L.; Pradeep, T. Rapid Synthesis of $\mathrm{C}-\mathrm{TiO}_{2}$ : Tuning the Shape from Spherical to Rice Grain Morphology for Visible Light Photocatalytic Application. ACS Sustain. Chem. Eng. 2015, 3, 1321-1329. [CrossRef]

14. Nyamukamba, P.; Tichagwa, L.; Ngila, J.C.; Petrik, L. Plasmonic metal decorated titanium dioxide thin films for enhanced photodegradation of organic contaminants. J. Photochem. Photobiol. A Chem. 2017, 343, 85-95. [CrossRef]

15. Morikawa, T.; Asahi, R.; Ohwaki, T.; Aoki, K.; Taga, Y. Band-Gap Narrowing of Titanium Dioxide by Nitrogen Doping. Jpn. J. Appl. Phys. 2001, 40, L561-L563. [CrossRef]

16. Palanivelu, K.; Im, J.S.; Lee, Y.-S. Carbon Doping of $\mathrm{TiO}_{2}$ for Visible Light Photo Catalysis-A review. Carbon Lett. 2007, 8, 214-224. [CrossRef]

17. Kanade, K.; Kale, B.; Baeg, J.-O.; Lee, S.M.; Lee, C.W.; Moon, S.-J.; Chang, H. Self-assembled aligned Cu doped $\mathrm{ZnO}$ nanoparticles for photocatalytic hydrogen production under visible light irradiation. Mater. Chem. Phys. 2007, 102, 98-104. [CrossRef]

18. Wang, J.; Huang, B.; Wang, Z.; Qin, X.; Zhang, X. Synthesis and characterization of C, N-codoped $\mathrm{TiO}_{2}$ nanotubes/nanorods with visible-light activity. Rare Met. 2011, 30, 161-165. [CrossRef]

19. Cheng, X.; Yu, X.; Xing, Z.; Yang, L. Synthesis and characterization of $\mathrm{N}$-doped $\mathrm{TiO}_{2}$ and its enhanced visible-light photocatalytic activity. Arab. J. Chem. 2016, 9 (Suppl. 2), S1706-S1711. [CrossRef]

20. Tijani, J.O.; Fatoba, O.O.; Totito, T.C.; Roos, W.D.; Petrik, L.F.; Info, A. Synthesis and characterization of carbon doped $\mathrm{TiO}_{2}$ photo-catalysts supported on stainless steel mesh by sol-gel method Original Articles. Carbon Lett. 2017, 22, 48-59. [CrossRef]

21. Yu, C.; $\mathrm{Yu}$, J.C.-M. A Simple Way to Prepare C-N-Codoped $\mathrm{TiO}_{2}$ Photocatalyst with Visible-Light Activity. Catal. Lett. 2009, 129, 462-470. [CrossRef]

22. Li, F.; Zhou, J.; Du, C.; Li, W.; Wang, Y.; He, G.; He, Q. Preparation and photocatalytic properties of porous C and $\mathrm{N}$ co-doped $\mathrm{TiO}_{2}$ deposited on brick by a fast, one-step microwave irradiation method. J. Environ. Sci. 2017, 60, 24-32. [CrossRef]

23. Mohamed, M.A.; Othman, M.H.D.; Zain, M.M.; Minggu, L.J.; Kassim, M.B.; Salehmin, M.N.I.; Rosmi, M.S.; Salleh, W.N.W.; Othman, M.H.D. Concurrent growth, structural and photocatalytic properties of hybridized C, $\mathrm{N}$ co-doped $\mathrm{TiO}_{2}$ mixed phase over g-C3N4 nanostructured. Scr. Mater. 2018, 142, 143-147. [CrossRef]

24. Osin, O.A.; Yu, T.; Cai, X.; Jiang, Y.; Peng, G.; Cheng, X.; Li, R.; Qin, Y.; Lin, S. Photocatalytic Degradation of 4-Nitrophenol by $\mathrm{C}, \mathrm{N}-\mathrm{TiO}_{2}$ : Degradation Efficiency vs. Embryonic Toxicity of the Resulting Compounds. Front. Chem. 2018, 6, 192. [CrossRef] 
25. Thamaphat, K.; Limsuwan, P.; Ngotawornchai, B. Phase Characterization of $\mathrm{TiO}_{2}$ Powder by XRD and TEM. Nat. Sci. 2008, 42, 357-361.

26. Xie, C.; Yang, S.; Li, B.; Wang, H.; Shi, J.-W.; Li, G.; Niu, C. C-doped mesoporous anatase $\mathrm{TiO}_{2}$ comprising $10 \mathrm{~nm}$ crystallites. J. Colloid Interface Sci. 2016, 476, 1-8. [CrossRef]

27. Zhang, Q. Effects of calcination on the photocatalytic properties of nanosized $\mathrm{TiO}_{2}$ powders prepared by $\mathrm{TiCl}_{4}$ hydrolysis. Appl. Catal. B Environ. 2000, 26, 207-215. [CrossRef]

28. Geng, J.; Yang, N.; Zhu, J.; Chen, D.; Jiang, Z. Nitrogen-doped $\mathrm{TiO}_{2}$ nanotubes with enhanced photocatalytic activity synthesized by a facile wet chemistry method. Mater. Res. Bull. 2009, 44, 146-150. [CrossRef]

29. Wu, S.; Gao, A.; Wang, Y.; Xu, L. Modification of polyacrylonitrile stabilized fibers via post-thermal treatment in nitrogen prior to carbonization and its effect on the structure of carbon fibers. J. Mater. Sci. 2018, 53, 8627-8638. [CrossRef]

30. Cagnina, S.; Rotureau, P.; Singh, S.; Turcotte, R.; Fayet, G.; Adamo, C. Theoretical and Experimental Study of the Reaction between Ammonium Nitrate and Sodium Salts. Ind. Eng. Chem. Res. 2016, 55, 12183-12190. [CrossRef]

31. Shao, G.-S.; Zhang, X.-J.; Yuan, Z.-Y. Preparation and photocatalytic activity of hierarchically mesoporous-macroporous $\mathrm{TiO}_{2}-\mathrm{xNx}$. Appl. Catal. B Environ. 2008, 82, 208-218. [CrossRef]

32. Sánchez-Soto, P.J.; Avilés, M.; Del Río, J.; Ginés, J.; Pascual, J.; Pérez-Rodríguez, J. Thermal study of the effect of several solvents on polymerization of acrylonitrile and their subsequent pyrolysis. J. Anal. Appl. Pyrolysis 2001, 58, 155-172. [CrossRef]

33. Darányi, M.; Sarusi, I.; Sápi, A.; Kukovecz, Á.; Konya, Z.; Erdőhelyi, A. Characterization of carbon thin films prepared by the thermal decomposition of spin coated polyacrylonitrile layers containing metal acetates. Thin Solid Films 2011, 520, 57-63. [CrossRef]

34. Laffont, L.; Monthioux, M.; Serin, V.; Mathur, R.; Guimon, C.; Guimon, M. An EELS study of the structural and chemical transformation of PAN polymer to solid carbon. Carbon 2004, 42, 2485-2494. [CrossRef]

35. Huang, Y.; Ho, W.; Lee, S.-C.; Zhang, L.; Li, G.; Yu, J.C.-M. Effect of Carbon Doping on the Mesoporous Structure of Nanocrystalline Titanium Dioxide and Its Solar-Light-Driven Photocatalytic Degradation of NOx. Langmuir 2008, 24, 3510-3516. [CrossRef] [PubMed]

36. Guo, Y.; Guo, T.; Chen, J.; Wei, J.; Bai, L.; Ye, X.; Ding, Z.; Xu, W.; Zhou, Z. Synthesis of C-N-S co-doped $\mathrm{TiO}_{2}$ mischcrystal with an isobandgap characteristic and its photocatalytic activity under visible light. Catal. Sci. Technol. 2018, 8, 4108-4121. [CrossRef]

37. Abdullah, A.M.; Al-Thani, N.J.; Tawbi, K.; Al-Kandari, H. Carbon/nitrogen-doped $\mathrm{TiO}_{2}$ : New synthesis route, characterization and application for phenol degradation. Arab. J. Chem. 2016, 9, 229-237. [CrossRef]

38. Wang, M.; Han, J.; Hu, Y.; Rong, G. Mesoporous $\mathrm{C}, \mathrm{N}$-codoped $\mathrm{TiO}_{2}$ hybrid shells with enhanced visible light photocatalytic performance. RSC Adv. 2017, 7, 15513-15520. [CrossRef]

39. Zhang, J.; Xing, Z.; Cui, J.; Li, Z.; Tan, S.; Yin, J.; Zou, J.; Zhu, Q.; Zhou, W. C,N co-doped porous TiO 2 hollow sphere visible light photocatalysts for efficient removal of highly toxic phenolic pollutants. Dalton Trans. 2018, 47, 4877-4884. [CrossRef] [PubMed]

40. Ghazzal, M.N.; Wojcieszak, R.; Raj, G.; Gaigneaux, E. Study of mesoporous CdS-quantum-dot-sensitized $\mathrm{TiO}_{2}$ films by using X-ray photoelectron spectroscopy and AFM. Beilstein J. Nanotechnol. 2014, 5, 68-76. [CrossRef] [PubMed]

41. Jia, T.; Fu, F.; Yu, D.; Cao, J.; Sun, G. Facile synthesis and characterization of $\mathrm{N}$-doped $\mathrm{TiO}_{2} / \mathrm{C}$ nanocomposites with enhanced visible-light photocatalytic performance. Appl. Surf. Sci. 2018, 430, 438-447. [CrossRef]

42. Igathinathane, C.; Pordesimo, L.; Columbus, E.; Batchelor, W.; Methuku, S.; Cannayen, I. Shape identification and particles size distribution from basic shape parameters using ImageJ. Comput. Electron. Agric. 2008, 63, 168-182. [CrossRef]

43. Igathinathane, C.; Pordesimo, L.; Batchelor, W.; Cannayen, I. Major orthogonal dimensions measurement of food grains by machine vision using ImageJ. Food Res. Int. 2009, 42, 76-84. [CrossRef]

44. Chen, T.; Xia, Y.; Jia, Z.; Liu, Z.; Zhang, H. Synthesis, Characterization, and Tribological Behavior of Oleic Acid Capped Graphene Oxide. J. Nanomater. 2014, 2014, 1-8. [CrossRef]

45. Carp, O.; Huisman, C.; Reller, A. Photoinduced reactivity of titanium dioxide. Prog. Solid State Chem. 2004, 32, 33-177. [CrossRef] 
46. Li, S.; Gong, Y.; Yang, Y.; He, C.; Hu, L.; Zhu, L.; Sun, L.; Shu, D. Recyclable CNTs/Fe $3 \mathrm{O}_{4}$ magnetic nanocomposites as adsorbents to remove bisphenol A from water and their regeneration. Chem. Eng. J. 2015, 260, 231-239. [CrossRef]

47. Gilmour, C.R.; Ray, A.; Zhu, J.; Ray, M.B. Photocatalytic Performance of Titanium Dioxide Thin Films from Polymer-Encapsulated Titania. Ind. Eng. Chem. Res. 2013, 52, 17800-17811. [CrossRef]

48. Sakthivel, S.; Kisch, H. Daylight Photocatalysis by Carbon-Modified Titanium Dioxide. Angew. Chem. Int. Ed. 2003, 42, 4908-4911. [CrossRef] [PubMed]

49. Tijani, J.; Mouele, M.E.S.; Fatoba, O.; O Babajide, O.; Petrik, L.F. Degradation of bisphenol-A by dielectric barrier discharge system: Influence of polyethylene glycol stabilized nano zero valent iron particles. Adv. Nat. Sci. Nanosci. Nanotechnol. 2017, 8, 035013. [CrossRef]

50. Li, J.; Zhang, J.Z. Optical properties and applications of hybrid semiconductor nanomaterials. Coord. Chem. Rev. 2009, 253, 3015-3041. [CrossRef]

51. Chen, Y.; Dionysiou, D.D. A comparative study on physicochemical properties and photocatalytic behavior of macroporous $\mathrm{TiO}_{2}-\mathrm{P} 25$ composite films and macroporous $\mathrm{TiO}_{2}$ films coated on stainless steel substrate. Appl. Catal. A Gen. 2007, 317, 129-137. [CrossRef]

52. Wu, Y.-C.; Ju, L.-S. Annealing-free synthesis of $\mathrm{CN}$ co-doped $\mathrm{TiO}_{2}$ hierarchical spheres by using amine agents via microwave-assisted solvothermal method and their photocatalytic activities. J. Alloy Compd. 2014, 604, 164-170. [CrossRef]

53. Saravanan, R.; Gupta, V.K.; Narayanan, V.; Stephen, A. Comparative study on photocatalytic activity of ZnO prepared by different methods. J. Mol. Liq. 2013, 181, 133-141. [CrossRef]

54. Khan, M.M.; Ansari, S.A.; Pradhan, D.; Ansari, M.O.; Han, D.H.; Lee, J.; Cho, M.H. Band gap engineered TiO 2 nanoparticles for visible light induced photoelectrochemical and photocatalytic studies. J. Mater. Chem. A 2014, 2, 637-644. [CrossRef]

55. Khan, M.M.; Adil, S.F.; Al-Mayouf, A.M. Metal oxides as photocatalysts. J. Saudi Chem. Soc. 2015, 19, $462-464$. [CrossRef]

56. Gnanasekaran, L.; Hemamalini, R.; Ravichandran, K. Synthesis and characterization of $\mathrm{TiO}_{2}$ quantum dots for photocatalytic application. J. Saudi Chem. Soc. 2015, 19, 589-594. [CrossRef]

57. Shriver, D.F.; Atkins, P.W.; Langford, C.H. Inorganic Chemistry, 2nd ed.; International Student Edition; Oxford University Press: Oxford, UK; Melbourne, Australia; Tokyo, Japan, 1994.

58. Mu, Y.; Yu, H.-Q.; Zheng, J.-C.; Zhang, S. TiO 2 -mediated photocatalytic degradation of Orange II with the presence of Mn2+ in solution. J. Photochem. Photobiol. A Chem. 2004, 163, 311-316. [CrossRef]

59. Yin, W.-J.; Tang, H.; Wei, S.-H.; Al-Jassim, M.; Turner, J.; Yan, Y. Band structure engineering of semiconductors for enhanced photo electrochemical water splitting: The case of $\mathrm{TiO}_{2}$. Phys. Rev. B 2010, 82, 045106. [CrossRef]

60. Ma, X.; Wu, Y.; Lu, Y.; Xu, J.; Wang, Y.; Zhu, Y. Effect of Compensated Codoping on the Photo electrochemical Properties of Anatase $\mathrm{TiO}_{2}$ Photocatalyst. J. Phys. Chem. C 2011, 115, 16963-16969. [CrossRef]

61. Fujishima, A.; Zhang, X.; Tryk, D. TiO 2 photocatalysis and related surface phenomena. Surf. Sci. Rep. 2008, 63, 515-582. [CrossRef]

62. Ikoma, T.; Zhang, Q.; Saito, F.; Akiyama, K.; Tero-Kubota, S.; Kato, T. Radicals in the Mechanochemical Dechlorination of Hazardous Organochlorine Compounds Using CaO Nanoparticles. Bull. Chem. Soc. Jpn. 2001, 74, 2303-2309. [CrossRef]

63. Haque, S.A.; Tachibana, Y.; Willis, R.L.; Moser, J.-E.; Grätzel, M.; Klug, D.R.; Durrant, J.R. Parameters Influencing Charge Recombination Kinetics in Dye-Sensitized Nanocrystalline Titanium Dioxide Films. J. Phys. Chem. B 2000, 104, 538-547. [CrossRef]

64. Prokes, S.; Gole, J.L.; Chen, X.; Burda, C.; Carlos, W.E. Defect-Related Optical Behavior in Surface Modified $\mathrm{TiO}_{2}$ Nanostructures. Adv. Funct. Mater. 2005, 15, 161-167. [CrossRef]

65. MacNeil, J.H.; Berseth, P.A.; Bruner, E.L.; Perkins, T.L.; Wadia, Y.; Westwood, G.; Trogler, W.C. Mechanism of Nitrous Oxide Formation by Metal-Catalyzed Reduction of Nitric Oxide in Aqueous Solution. J. Am. Chem. Soc. 1997, 119, 1668-1675. [CrossRef]

66. Kogelschatz, U.; Eliasson, B.; Egli, W. Dielectric-Barrier Discharges. Principle and Applications. Le J. de Phys. Colloq. 1997, 7, C4-47-C4-66. [CrossRef]

67. Kogelschatz, U. Dielectric-Barrier Discharges: Their History, Discharge Physics, and Industrial Applications. Plasma Chem. Plasma Process. 2003, 23, 1-46. [CrossRef] 
68. Nehra, V.; Kumar, A.; Dwivedi, H.K. Atmospheric Non-Thermal Plasma Sources. Int. J. Eng. 2008, 2, 53-68.

69. Lopez, J.L. Dielectric Barrier Discharge, Ozone Generation, and Their Applications; Complex Plasmas Summer Institute: Jersey City, NJ, USA, 2008.

70. Valinčius, V.; Grigaitienè, V.; Tamošiūnas, A. Report on the Different Plasma Modules for Pollution Removal; Plasma for Environ Protect, Lithuanian Energy Institute: Kaunas, Lithuania, 2012; pp. 1-49.

71. Totito, T.C. Photocatalytic Activity of Supported $\mathrm{TiO}_{2}$ Nanocrystals. Master's Thesis, University of the Western Cape, Cape Town, South Africa, 2013.

72. Kuang, L.; Zhao, Y.; Liu, L. Photodegradation of Orange II by mesoporous $\mathrm{TiO}_{2}$. J. Environ. Monit. 2011, 13, 2496. [CrossRef]

73. Sayed, E.; El-Ashtoukhy, Z. Removal of Indigo Carmine Dye from Synthetic Wastewater by Electrochemical Oxidation in a New Cell with Horizontally Oriented Electrodes. Int. J. Electrochem. Sci. 2013, 8, 846-858.

74. Mouele, E.S.M.; Dinu, M.; Parau, A.C.; Missengue, R.; Vladescu, A.; Petrik, L.F.; Braic, M. Dinu Evaluation of Photocatalysis Effect of Stainless Steel Mesh Coated with Nitrides, Oxynitrides and Transition Metals Cr and Ti on the Degradation of Orange II Dye. Proceedings 2019, 29, 14. [CrossRef]

(C) 2020 by the authors. Licensee MDPI, Basel, Switzerland. This article is an open access article distributed under the terms and conditions of the Creative Commons Attribution (CC BY) license (http://creativecommons.org/licenses/by/4.0/). 